\title{
1 Essential functions of MLL1 and MLL2 in retinal development and cone cell 2 maintenance
}

3

4

5

6
Chi Sun ${ }^{1}$, Xiaodong Zhang ${ }^{1}$, Philip A. Ruzycki ${ }^{1}$ and Shiming Chen ${ }^{1,2 *}$

${ }^{1}$ Department of Ophthalmology and Visual Sciences, ${ }^{2}$ Department of Developmental Biology, Washington University, Saint Louis, Missouri, USA

*To whom the correspondence should be addressed.

Mailing address:

660 South Euclid Avenue, MSC-8096-06-06,

St. Louis, MO 63110, USA

Tel. 3147474350

Fax. 3147474211

chenshiming@wustl.edu

Running title: MLL1/MLL2 in retina

Keywords: MLL1 (KMT2A), MLL2 (KMT2B), conditional knockout, retinal development, functional maintenance, histone modifications, gene expression. 


\section{ABSTRACT}

MLL1 (KMT2A) and MLL2 (KMT2B) are homologous members of the mixed-lineage leukemia (MLL) variants have been associated with neurological and psychological disorders, but little is known about their roles and mechanism of action in CNS development. Using mouse retina as a model, we previously reported MLL1's role in retinal neurogenesis and horizontal cell maintenance. Here we determine roles of

35 MLL2 and MLL1/MLL2 together in retinal development using conditional knockout (CKO) mice. displayed null light responses in electroretinogram; thin retinal layers, including shorter photoreceptor outer segments with impaired phototransduction gene expression; and reduced numbers of M-cones, horizontal and amacrine neurons, followed by fast retinal degeneration. Despite moderately reduced progenitor cell proliferation at $\mathrm{P} 0$, the neurogenic capacity was largely maintained in double CKO mutants. However, upregulated apoptosis and reactive gliosis were detected during postnatal retinal

43 development. Finally, the removal of both MLLs in fated rods produced a normal phenotype, but the

$44 \mathrm{CKO}$ in $\mathrm{M}$-cones impaired $\mathrm{M}$-cone function and survival, indicating both cell non-autonomous and

45 autonomous mechanisms. Altogether, our results suggest that MLL1/MLL2 play redundant roles in

46 maintaining specific retinal neurons after cell fate specification and are essential for establishing

47 functional neural networks. 


\section{INTRODUCTION}

The mixed-lineage leukemia (MLL) family of histone lysine methyltransferases (KMTs) catalyze the methylation at lysine (K) 4 of histone H3 (Crump \& Milne, 2019; Shilatifard, 2008). Their products, mono-, di- and tri-methylation of $\mathrm{H} 3 \mathrm{~K} 4$ are considered activating histone marks that are found at promoters of transcribed genes (Eissenberg \& Shilatifard, 2010; Gu \& Lee, 2013). The MLL family has six members, namely, MLL1 (KMT2A), MLL2 (KMT2B), MLL3 (KMT2C), MLL4 (KMT2D), SET1DA and SET1DB, all of which contain a conserved catalytic SET domain (Allis et al., 2007; Crump \& Milne, 2019). These MLL enzymes usually form large multi-protein complexes (Dou et al., 2006; Shinsky et al., 2015; Yokoyama et al., 2004) that mediate chromatin remodeling and transcriptional regulation during tissue genesis (Cenik \& Shilatifard, 2021; Glaser et al., 2006; Krivtsov \& Armstrong, 2007; Slany, 2016). MLL1/MLL2 form a distinct macromolecular complex (Crump \& Milne, 2019; Sze \& Shilatifard, 2016) found in many cell types of the central nervous system (CNS) (Brightman et al., 2018; Jakovcevski et al., 2015; Kerimoglu et al., 2017). Human mutations in MLL1 (KMT2A) and MLL2 (KMT2B) have been associated with cancer and syndromic neurological and psychiatric disorders, such as dystonia, intellectual disability and autism with variable age onsets (Jones et al., 2012; Meyers et al., 2017). However, their functions and mechanisms of action in the CNS development and neuronal disease pathogenesis remain to be elucidated.

67 The retina is the tissue of the CNS specialized for the vision sensation. It consists of conserved and well68 characterized neuronal cell types, making it an ideal model for studying MLL functions in neurogenesis, neural network formation and maintenance. Retinal cells are organized into a multi-laminar structure in a mature retina (Bassett \& Wallace, 2012; Cepko, 2014; Cepko et al., 1996; Young, 1985). The outer nuclear layer (ONL) contains rod and cone photoreceptor cells, where the light signal is converted into

72 the neuronal signal. The inner nuclear layer (INL) hosts neurons of horizontal (HC), bipolar (BC) and 73 amacrine cells (AC), as well as Müller glia (MG). The ganglion cell layer (GCL) contains retinal ganglion 
74

75

76

77

78

79

80

81

82

83

84

85

86

87

88

89

90

91

92

93

94

95

96

97

98

99

cells (GC) innervating to the brain. Synaptic connections between these layers form two additional layers

known as the inner (IPL) and outer plexiform layers (OPL). Cell-type specification of the retina is largely conserved across vertebrate species (Austin \& Cepko, 1995; Livesey \& Cepko, 2001; Lu et al., 2020;

Stenkamp, 2015; Wu et al., 2018). In mice, GC, cone photoreceptors and HC are fated in the first wave of cell birth during prenatal retinal neurogenesis, followed by the later birth waves of AC, rod

photoreceptors, BC and MG during postnatal days (P) 0 to P5 (Cepko, 2014; Emerson et al., 2013; Hafler et al., 2012; Turner et al., 1990; Young, 1985). After cell fate specification, neuronal differentiation and synaptogenesis begin to establish connections between rod/cone primary neurons and secondary/tertiary neurons. By the end of three weeks, a functional neural network is established to mediate visual signal transmission and processing (Blanks et al., 1974; Furukawa et al., 2020; Guido, 2018; Soto et al., 2012; Szatko et al., 2020; Tian, 2004).

Retinal cell fate specification and differentiation are regulated by a network of transcription factors (TF) (Hennig et al., 2008; Mellough et al., 2019; Swaroop et al., 2010). CHX10 (also known as VSX2) is one of the earliest expressed TFs in the presumptive neural retina, and is required for retinal progenitor cell (RPC) proliferation and neurogenesis (Burmeister et al., 1996; Green et al., 2003; Liu et al., 1994; Livnebar et al., 2006). CHX10 is also required for bipolar cell specification at a later development stage (Kim et al., 2008; Morrow et al., 2008). OTX2 is essential for establishing the photoreceptor lineage (Koike et al., 2007; Nishida et al., 2003) by inducing the expression of CRX, an OTX-like TF required for photoreceptor development and maintenance (Chen et al., 1997; Furukawa et al., 1997; Hennig et al., 2008). TFs acting downstream of OTX2/CRX govern photoreceptor specification, including NRL (Mears et al., 2001) for rods, THRB2 (Roberts et al., 2006) and RXRG (Roberts et al., 2005) for cones, specifically in mouse, for short-wavelength (S) and medium-wavelength (M) cones. TFs required for the development of INL and GCL neurons include Onecut1 (OC1) and PROX1 for horizontal cells (Dyer et al., 2003; Wu et al., 2013), PAX6 for amacrine cells (Remez et al., 2017), and POU4F1 (BRN3A) for ganglion cells (Nadal-Nicolás et al., 2009). 
101 In order to express specific genes in a given cell type, the chromatin at these gene loci must be configured

102 to allow access by the transcription machinery. Specific TFs can regulate local chromatin remodeling

103 during the retinal development by recruiting co-activators and histone modification enzymes at target

104 genes (Li et al., 2007; Zhang et al., 2015). For example, CRX is required for the postnatal developing

105 photoreceptors to gain DNA accessibility and write active histone marks H3K4me3 and H3K27Ac at

106 photoreceptor gene loci (Ruzycki et al., 2018), which is important for the transcription cascade and visual

107 function.

108

We previously reported, using conditional knockout mice, that MLL1 plays essential roles in regulating retinal progenitor cell proliferation, maintenance of horizontal neurons and formation of functional synapses between photoreceptors and inner neurons (Brightman et al., 2018). Here we aimed to unveil the roles of MLL2 and MLL1/MLL2 together in the development and maintenance of retinal neurons by

113 characterizing the phenotypes of retina-specific knockout of Mll2 and both Mll1 and Mll2. We found that 114 during the functional development, two MLLs played redundant roles in maintaining the retinal structure 115 and function of photoreceptors and three types of inner retinal neurons. Both cell autonomous and non116 autonomous functions contributed to cone/rod maintenance. These results implicated complex 117 mechanisms of action of MLL1 and MLL2 in the retinal development and maintenance.

\section{RESULTS}

Generation of $M l l 1$ and $M l l 2$ conditional knockouts in mouse retinae.

123 Due to the embryonic lethality of Mll1 or Mll2 deficiency, we utilized Cre-LoxP-mediated conditional

124 knockout (CKO) to eliminate the function of each gene individually or simultaneously in selected retinal

125 cell types. Cre excision produced a non-functional MLL1 protein lacking the nuclear targeting sequences 
(NTS) (Gan et al., 2010) and/or a short non-functional MLL2 peptide resulted from a frameshift at exon 2

127 (Glaser et al., 2006) (Figure 1A). To investigate the roles of MLL1 and MLL2 in retinal neurogenesis, we crossed Mll fff and/or Mll2 fff mice to Chx10-Cre-iresGFP (Rowan \& Cepko, 2004) mice, which expressed Cre recombinase in retinal progenitor cells. To confirm the success of Cre-mediated excision, we performed quantitative RT-PCR (qRT-PCR) analysis to determine Mll1 and Mll2 transcript levels in the mutant retinae at postnatal day P0, P14, and 1 month (1MO) (Figure 1B-D). Detectable transcript levels of Mll1 and Mll2 were significantly reduced in $C h x 10 C r e^{+} M l l 1^{f f f} M_{l l} 2^{f f f}($ double CKO) retinae at all tested ages as compared to Chx10Cre- (CreNeg) samples with the lowest level seen at 1MO. Notably, at all tested ages, reduction of Mll1 or Mll2 transcript levels in the double CKO retinae was comparable to the corresponding single $C K O$. Furthermore, in either case of single $C K O$ retinae, no increase in the transcript level of the counterpart Mll gene was detected, suggesting no compensatory effect between Mll1 and Mll2 expression in single $C K O$ retinae.

\section{$M l l 1$ and $M l l 2$ deficiency perturbs retinal function more severely than each single $C K O$.}

141 We performed electroretinography (ERG) to determine the effects of Mll1 and Mll2 deficiency on the

142 retinal function. $1 \mathrm{MO}$ double $\mathrm{CKO}$ mutants showed no ERG responses in both dark-adapted (Figure 2A-

$143 \mathrm{~B}$, purple line) and light-adapted (Figure 2C, purple line) conditions, indicating the absence of both rod-

144 and cone-driven retinal function. In contrast, $1 \mathrm{MO}$ single $C K O$ mutants produced detectable ERG

145 responses (Figure 2A-C, red and green lines), but had significantly decreased A and B wave amplitudes at

146 high light intensities as compared to those of CreNeg littermates. The ERG reductions were more

147 pronounced in $C h x 10 C r e^{+} M l l 1^{f f f}$ than in $C h x 10 C r e^{+} M l l 2^{f f f}$ (Figure 2A-C, green line vs red line). Similar

148 patterns of ERG changes were also noticeable at 2MO (Supplemental Figure 1A). These results provided

149 the first piece of evidence for distinct and redundant roles of MLL1/MLL2 in the development and

150 maintenance of retinal function. Compound heterozygous mutants $C h x 10 C r e^{+} M l l 1^{W T / f} M l l 2^{f f f}$ and

151 Chx10Cre ${ }^{+} \mathrm{Mll}^{\mathrm{fff}} \mathrm{Mll2}^{\text {WT/f }}$ showed similar ERG defects as those of the single CKO mutants (Supplemental 
Figure 1B-C) at $1 \mathrm{MO}$ and 2MO, indicating that at least one copy of Mll1 or Mll2 allele was essential for retinal function.

\section{$M l l 1$ and $M l l 2$ double $C K O$ mice develop thinner retinae and undergo fast retinal degeneration in} young adults.

To determine if the ERG defects in the mutant retinae were indicative of changes in the retinal structure and cellular morphology, we firstly examined the retinal cross-sections by hematoxylin-and-eosin (H\&E) staining. At 1MO, all mutants displayed well-laminated neurons (Figure 3A). However, as compared to the CreNeg control, the double CKO retinae had significant reductions in overall retinal thickness, including ONL (Figure 3B), INL (Figure 3C), and outer segments (OS) of the photoreceptors (Figure 3D). Mislocalized cells were found (indicated by asterisks in Figure 3A) within the OS and IPL of the double $C K O$ mutant. At $2 \mathrm{MO}$, single $C K O$ mice retained the laminated retinal morphology, despite a few mislocalized cells found at the IPL (Figure 3A, bottom left panels). In contrast, the double CKO retinae became much thinner than that at $1 \mathrm{MO}$, suggesting severe degeneration and cell death (Figure $3 \mathrm{~A}$ ). By $3 \mathrm{MO}$, both ONL and INL of the double CKO retinae degenerated further with only 1-2 rows of cells remaining in each layer (Figure 3A). Also, the OS length in the double CKO retinae was further reduced at $2 \mathrm{MO}$ and $3 \mathrm{MO}$. Thus, loss of both Mll1 and Mll2 resulted in failure of morphological maintenance of the retinae, particularly affecting neuronal survival in the ONL and INL. Interestingly, 2MO compound

171 heterozygous mutants, $C h x 10 C r e^{+} M l l 1^{W T / f} M l l 2^{f f f}$ and $C h x 10 C r e^{+} M l l 1^{f f f} M l l 2^{W T / f}$ appeared less affected in

172 retinal morphology as compared to the double mutants (Supplemental Figure 2A), again suggesting at

173 least one copy of either Mlll or Mll2 allele was required for the maintenance of retinal integrity.

175 We next examined changes in the retinal morphology at early ages of postnatal development. No 176 morphological or thickness abnormalities were found in the new-born $\mathrm{P} 0$ double CKO retinae

177 (Supplemental Figure 3A, B). However, decreased ONL and INL thickness was found in P14 double 
CKO retinae as compared to CreNeg samples (Supplemental Figure 3C, D). These results suggested that Mll1 and Mll2 deficiency interfered with maintenance but not genesis of retinal neurons.

\section{$M l l 1$ and $M l l 2$ deficiency induces progressive degeneration of M-cones, horizontal and amacrine cells.}

To determine if Mlll and Mll2 deficiency during the retinal development displayed cell-type specific effects, retinal cross-sections of $1 \mathrm{MO}$ mutants and controls were immunostained with cell-type specific markers. Given ERG deficits in the double CKO mutants, we firstly assessed the staining of rod and cone Opsins (Figure 4A-C). Rhodopsin (Rho) staining was correctly localized to the OS in the double KO retina (Figure 4A). However, consistent with the results of H\&E staining (Figure 3D), the length of Rho+ OS appeared shorter in the mutant than the CreNeg control (Figure 4A). Next, we stained for cone opsins. In mice, $\mathrm{M}$ and $\mathrm{S}$ cone subtypes were organized in dorsal-ventral counter-gradients, with $\mathrm{M}$-opsin+ cones predominantly found in the dorsal retina and S-opsin+ cones in the ventral retina (Applebury et al., 2000). In the double $C K O$ retinae, both $\mathrm{M}$-opsin and S-opsin labeled cells were detected with the expected dorsal/ventral orientation (Figure 4B-C). However, while the number of M-opsin+ cells was reduced to about $20 \%$ of the control, no significant reduction of S-opsin+ cells was found (Figure 4H).

Next, we assessed changes of neuronal cell types in the inner retina. The double CKO retinae displayed significantly decreased numbers (10-30\% remaining) of Calbindin+ horizontal cells, and Calretinin+ amacrine cells (Figure 4D, E, H). In contrast, the numbers of PKC $\alpha+$ rod-on bipolar cells (Figure 4D) and Brn3a+ ganglion cells (Figure 4F) in mutants generally remained comparable to the controls (Figure 4H). Interestingly, $1 \mathrm{MO}$ single $C K O$ retinae also had decreased numbers of $\mathrm{M}$-cones, horizontal cells, and amacrine cells (Supplemental Figure 4), but the degree of reduction was less severe than that in the double CKO retinae. Taken together, the distinct and redundant roles of MLL1 and MLL2 were essential for the integrity of M-cones, horizontal cells, and amacrine cells. 
We also examined the number and morphological features of Müller glia by glutamate synthetase (GS) compared to the control (Figure 4G), with cell bodies locating at the INL and endfeet terminating at the basal lamina. Mutant retinae also had similar numbers of Müller glia (Figure 4H), suggesting the development of these glial cells was generally unaffected in the mutants.

211 To determine if the loss of selected retinal cell types was due to defective cell type specification or 212 maintenance, we examined the early cell types in P0 retinae by immunostaining (Supplemental Figure 5).

213 We used antibodies targeting Retinoid X Receptor Gamma (RXRg) to label early fated cones, Onecut1 214 for early horizontal cells, Activating enhancer binding protein 2 alpha (AP2 $\alpha$ ) for early amacrine cells, 215 and Paired box 6 (Pax6) for late-born RPCs (Supplemental Figure 5A). Cell count analysis showed that 216 the numbers of these four cell types were comparable in the double CKO and CreNeg retinae

217 (Supplemental Figure 5B), indicating that the production of early-born neurons and Pax6+ late RPCs was not severely affected in the double $C K O$ retinae at $\mathrm{P} 0$. the cell fate specification of all retinal neurons was completed (Figure 5A). The cell numbers of these cell

222 types in mutants were lower than CreNeg samples (Figure 5B), but the degree of reduction at P14 (20-

$22350 \%)$ was less than that at $1 \mathrm{MO}(80-90 \%)$, indicating a progressive loss of cones, horizontal and amacrine

224 cells in the double $C K O$ retinae during the postnatal retinal development.

226 To determine if programmed cell death contributed to the loss of neurons, we immunostained mutant

227 retinae with activated caspase 3 . At P0, a significant increase in the number of apoptotic cells (activated

228 caspase 3+) were detected in mutant compared to CreNeg samples (Supplemental Figure 6A-B).

229 Increased activated caspase 3+ cells were also notable at 1MO mutant retinae (Supplemental Figure 6C). 
We also assessed the expression of pro- and anti-apoptotic genes. The transcript levels of the proapoptotic gene Bcl-2-associated X (Bax) were upregulated in P14 double CKO retinae and more significantly in $1 \mathrm{MO}$ double $C K O$ retinae relative to the CreNeg control, while the expression of the antiapoptotic gene $B$-cell lymphoma 2 ( $B c l 2)$ was insignificantly reduced in mutants (Supplemental Figure 6D). These data suggested that in double $C K O$ retinae, the intrinsic apoptosis was initiated during the retinal development and accelerated at $1 \mathrm{MO}$. This was consistent with retinal thinning and cell loss detected at P14 and 1MO, explaining the rapid degeneration afterwards.

To determine if Mll1/Mll2 deficiency induced reactive gliosis, we performed immunostaining of Glial fibrillary acidic protein (GFAP) on retinal cross-sections of the double CKO mice. GFAP was the intermediate filament protein in retinal glia, its immunoreactivity indexed potential gliosis and correlation of neural damage. At 1MO, GFAP immunoreactivity was minimal in the control retinae, but was drastically intensified in the double $C K O$ retinae (Figure 6A), indicating severe reactive gliosis. The GFAP+ reactive gliosis was lower in the single $C K O$ retinae than that in the double $C K O$ retinae. This high GFAP immunoreactivity in $1 \mathrm{MO}$ double $C K O$ retinae was confirmed by GFAP qRT-PCR (data not shown). The GFAP immunoreactivity was comparable in the $\mathrm{P} 14$ double $C K O$ retinae (Figure $6 \mathrm{~B}$ ) to the control. Thus, the glial activation in mutants likely occurred after eye-opening, accompanied by the loss of retinal integrity at both structural and functional levels.

\section{MLL1 and MLL2 regulate late progenitor cell proliferation in postnatal developing retina.}

Since cell proliferation defects were previously observed within P3 retinae of the $C h x 10 C r e^{+} M l l 1^{f / f}$ mutants (Brightman et al., 2018), we sought to determine if a similar phenotype could be found in the

253 double $C K O$ retinae at an early postnatal age. We performed Ki67 immunostaining for proliferating cells 254 in the retinal cross-sections of P0 samples (Figure 7A). The number of Ki67+ proliferative cells in the 255 double CKO retinae was decreased to $79 \%$ of control (Figure7B). We next examined if the cell cycle of 
Ki67+ proliferative cells was affected. Phospho-histone H3 (PH3) was used to label M-phase cells. PH3+

257 cells were found at the outer retinal neuroblast layer (NBL) of the double CKO and CreNeg retinae

258 (Figure 7A). We did not find a significant difference in Ki67+ and PH3+ co-labelled cells between these

259 samples. To detect S-phase cells in P0 retinae, 5-Ethynyl-2'-deoxyuridine (EdU) was IP-injected into P0

260 mouse pups, and retinae were harvested 4 hours later (Figure 7A right panel). The double CKO retinae

261 possessed fewer EdU+ cells than CreNeg control (Supplemental Figure 7A, 7C). More importantly, the

262 double $C K O$ retinae had a decrease in Ki67+/EdU+ co-labelled cells, down to $72 \%$ of the control (Figure

263 7B). These data suggested that Mll1 and Mll2 deficiency affected cell proliferation and cell cycle

264 dynamics in $\mathrm{P} 0$ retinae.

To determine impacts of Mll1\&Mll2 deficiency on the production of specific cell types from late-born retinal progenitor cells (RPC), we performed EdU pulse-chase experiments. EdU-labeled P0 proliferating cells were assessed for specified cell-types at P14 (Figure 7C, D). Firstly, at P14, there were fewer EdU+ cells in the double CKO retinae than in CreNeg controls (Supplemental Figure 7B, C). Secondly, the

271 as compared to the control, but those of rods, late-born amacrine cells and Müller glia remained

272 comparable (Figure 7C, D). These results suggested that, despite moderately reduced ON-bipolar cell

273 production from P0 progenitor cells, overall, the intrinsic neurogenesis program was not severely

274 compromised in the double $C K O$ retinae.

277 promoter occupancy of the active histone mark H3K4me3.

To unveil the molecular mechanisms for the cellular and functional defects in the double CKO retinae, we profiled specific gene expression changes at P14 and 1MO. qRT-PCR analysis showed there was a

281 general trend toward reduced expression with tested transcripts in double CKO retinae as compared to the 
CreNeg retinae, suggesting that Mll1/Mll2 deficiency had a negative impact on gene expression in general

(Figure 8A). However, the transcript level of lysine demethylase $6 B(K d m 6 b)$ was slightly upregulated in $1 \mathrm{MO}$ double $C K O$ retinae. The downregulation of the cell-type specific transcript levels supported the results of immunohistochemistry (Figures 4, 5), further confirming cell composition changes at these two ages. In particular, this downregulation was most prominent in three cell types (Figure 8A), M-cones (Opn1mw, 30-50\%), horizontal cells (Proxl, $\sim 60 \%)$ and amacrine cells (Pax6, $60 \%)$. Lastly, the changes in transcript expression at $1 \mathrm{MO}$ were more profound than those at P14, which was consistent with the progressive loss of the affected neurons. For example, the relative expression of OpnImw was reduced from 52\% at P14 to $34 \%$ at $1 \mathrm{MO}$. The relative expression of Rho decreased from insignificant $70 \%$ at $\mathrm{P} 14$ to significant $48 \%$ at $1 \mathrm{MO}$. These results, combined with the reduction of rod OS length at $1 \mathrm{MO}$, suggested that rod cell integrity was affected before degeneration peaks. Additionally, we performed qRT-PCR with early-born cell markers at P0, including Thrb and Rxrg (cones), Onecut1 (horizontal cells), Chx10 and Pax6 (RPCs). No expression changes were detected in P0 double CKO retinae relative to the control (Supplemental Figure 8), suggesting that early RPCs and their neurogenesis were unaffected by Mll1/Mll2 deficiency.

We also examined gene expression of several other components in the rod and cone phototransduction cascades. qRT-PCR was performed to analyze transcripts of $G$ protein subunit alpha transducin 1 (Gnat1), transducin 2 (Gnat2), Phosphodiesterase 6a (Pde6a), 6b (Pde6b), 6g (Pde6g), 6h (Pde6h). All tested genes besides Pde6a showed significant reduction in $1 \mathrm{MO}$ double $C K O$ retinae (Figure $8 \mathrm{~B}$ ). Notably, the relative expression of Gnat 1 and Pde6g was decreased to $25 \%$ and $14 \%$ of the control, respectively. These results suggested that the rod and cone phototransduction cascade was disrupted in $1 \mathrm{MO}$ double $\mathrm{KO}$ retinae, providing an explanation for the lack of ERG responses. In contrast, the single CKO samples only had moderate or insignificant changes in gene expression (Supplemental Figure 9). 
Since MLL1 and MLL2 function to methylate H3K4 at active gene promoters, we hypothesized that the gene misregulation in the mutants may be caused by the lack of the active histone mark $\mathrm{H} 3 \mathrm{~K} 4 \mathrm{me} 3$ at photoreceptor specific promoters. We performed whole-retina chromatin immunoprecipitation sequencing (ChIP-Seq) to compare the double CKO mutants with CreNeg controls. Because rods represented $70 \%$ of all retinal cells, ChIP data represented a primarily rod signal in bulk ChIP-Seq analysis of P14 and 1MO samples (before severe rod degeneration in the mutants). Biological replicates displayed $>98 \%$

313 concordance, indicating excellent reproducibility (Supplemental Figure 10A). Next, we compared the

314 ChIP signal between mutants and controls and identified differentially enriched peaks at each age as well 315 as those peaks that change over time in each model (Supplemental Figure 10B). To our surprise, there were only 279 peaks that displayed significant differences ( $>2$ fold-change, $\mathrm{P}<0.05$ ) in these comparisons

317 (Figure 8C). To understand the normal deposition of these histone modifications in retinal development, we analyzed the average change in signal over retinal development (E14-P21) (Aldiri et al., 2017). Peaks that were decreased in mutants generally showed consistent $\mathrm{H} 3 \mathrm{~K} 4 \mathrm{me} 3$ across development, while peaks gained in mutants showed very little deposition of any active marks in the controls. We inspected the must be responsible for the reduced expression of photoreceptor-specific genes.

\section{MLL1 and MLL2 are required for the maintenance of fated M-cones, but not rods.}

Although defective rod and cone phenotypes were seen in Chx10-Cre-mediated double CKO retinae, it was unclear if these phenotypes were stemmed from primary and/or secondary effects of Mll1/Mll2

331 deficiency. To address this question, we determined cell autonomy by investigating the effects of 
we crossed $\mathrm{Mll}^{\mathrm{fff}} \mathrm{Mll} 2^{\mathrm{fff}}$ mice to $\mathrm{Nrl}$-Cre mice (Brightman et al., 2016), which began to express Cre recombinase in developing rods soon after rod cell specification and sustained Cre expression in adult rods. We also ablated Mll1/Mll2 in fated M-cones by crossing Mll fff Mll fff mice to Mcone-Cre (HRGPCre) mice (Le et al., 2004), which expressed Cre recombinase in M-opsin+ cones beginning at early postnatal ages. H\&E staining of $1 \mathrm{MO} \mathrm{NrlCr} e^{+} \mathrm{Mlll}^{\mathrm{fff}} \mathrm{Mll}^{\mathrm{fff}}$ and $\mathrm{MconeCr} \mathrm{CM}^{+} \mathrm{Mll} \mathrm{ff}^{\mathrm{ff}} \mathrm{Mll}^{\mathrm{fff}}$ showed no apparent morphological abnormality (Figure 9A).

We next measured ERG responses in $1 \mathrm{MO} \mathrm{NrlCr} e^{+} \mathrm{Mll1}^{\mathrm{fff}} \mathrm{Mll}^{\mathrm{fff}}$ mice. No defects in dark-adapted A and comparable (data not shown). Furthermore, Rho immunostaining showed no significant difference in OS morphology and thickness (Figure 9C). Transcript-level expression analysis of rod-enriched genes by qRT-PCR detected no changes in 1MO mutant retinae relative to the control (Supplemental Figure 11A). maintenance of fated rods.

By comparison, $\mathrm{MconeCr} \mathrm{e}^{+} \mathrm{Mlll^{ff }} \mathrm{Mll}^{\mathrm{fff}}$ mice displayed cone functional and morphological defects. The amplitudes of light-adapted B waves of $1 \mathrm{MO} M c o n e C r e^{+} M l l 1^{f f f} M l l 2^{f / f}$ mice were significantly decreased as compared to controls (Figure 9D). 1MO MconeCre ${ }^{+} \mathrm{Mll1}^{\mathrm{fff}}$ and $\mathrm{MconeCr}^{+} \mathrm{Mll}^{\mathrm{fff}}$ mice also showed decreased ERG responses as compared to controls, but were less severe than $M c o n e C r e^{+} M l l 1^{f f f} M l l 2^{f f f}$ mice

354 (Figure 9D). These results suggested that MLL1 and/or MLL2 were required for the functional 355 maintenance of M-cones even after the cone differentiation.

357 We next performed immunostaining of Opn1mw (M-cones) together with PNA (all cones), or cone $358 \operatorname{arrestin}(\mathrm{Arr} 3)$ in retinal cross-sections of $1 \mathrm{MO}$ MconeCre ${ }^{+} \mathrm{Mll}^{\mathrm{fff}}, \mathrm{MconeCr}^{+} \mathrm{Mll}^{\mathrm{fff}}$, 
$\mathrm{MconeCr}^{+} \mathrm{Mll}^{\mathrm{fff}} \mathrm{Mll2}^{\mathrm{fff}}$ retinae (Figure 9E-F, Supplemental Figure 12). Quantification showed that the number of Opn1mw+ cones in $\mathrm{MconeCr} \mathrm{C}^{+} \mathrm{Mll1^{fff }} \mathrm{Mll}^{\mathrm{fff}}$ retinae was reduced to $50 \%$ of the control, while the numbers in $\mathrm{MconeCr}^{+} \mathrm{MllI}^{\mathrm{fff}}$ or $\mathrm{MconeCr} \mathrm{CM}^{+} \mathrm{Mll}^{\mathrm{ff}}$ was down to only 70-80\% (Figure 9F). To determine any spatial patterns associated with the cone number reduction, we performed M-opsin and PNA co-staining on $1 \mathrm{MO}$ whole-mount $M c o n e C r e^{+} M l l 1^{f f f} M_{l l} 2^{f f}$ retinae (Supplemental Figure 13A). As expected, in $1 \mathrm{MO}$ control samples, Opn1mw+ cones were largely localized to the dorsal retina

365 (Supplemental Figure 13A). By comparison, fewer Opn1mw+ cones were found in the dorsal region of MconeCre $^{+} \mathrm{Mll}^{\mathrm{fff}} \mathrm{Mll2}^{\mathrm{fff}}$ retinae (Supplemental Figure 13A). Cell count analysis showed that nearly half of Opn1mw+ (PNA+) cells were absent in the dorsal mutant retinae, while the cone cell numbers were comparable in the ventral retinae (Supplemental Figure 13B), confirming Mll1/Mll2 deficiency in cones specifically affected M-cone integrity. qRT-PCR analysis showed significantly decreased expression of OpnImw and Arr3 in $1 \mathrm{MO}$ MconeCre $\mathrm{Mll}^{\mathrm{fff}} \mathrm{Mll}^{\mathrm{fff}}$ retinae, but not in $\mathrm{MconeCr}^{+} \mathrm{MllI}^{\mathrm{fff}}$ or MconeCre $\mathrm{Mll}^{\mathrm{fff}}$ retinae (Supplemental Figure 11B-C), further confirming the immunostaining results.

372 Taken together, these results described the cell autonomous effect of Mll1/Mll2 deficiency on M-cone 373 functional maintenance.

\section{DISCUSSION}

Redundant roles of MLL1 and MLL2 in retinal development and maintenance.

MLL1 and MLL2 have been reported to play non-overlapping roles in development and cancer (Chen et al., 2017). In this manuscript, we used the conditional knockout strategy in mice to provide several pieces of evidence supporting that MLL1 and MLL2 redundant functions were required for the development and maintenance of neuronal function in the retina. 
When MLL1 or MLL2 was removed from Chx10+ retinal progenitor cells, similar phenotypic defects were observed, including moderately reduced photoreceptor responses to light stimuli (Figure 2,

Supplemental Figure 1), loss of M-cones, horizontal and amacrine cells (Supplemental Figure 4). Thus, MLL1 and MLL2 essentially functioned in the indistinguishable regulatory pathways during retinal development and maintenance. MLL1 contributed more than MLL2 in each pathway, as all observed phenotypes were more severe in $C h x 10 \mathrm{Cre}^{+} \mathrm{Mll}^{f f f}$ than $\mathrm{Chx} 10 \mathrm{Cr} \mathrm{e}^{+} \mathrm{Mll}^{\mathrm{fff}}$. In each single CKO retinae, there were no decreases or compensatory increases of transcript levels of the other $M l l$ gene.

When both MLL1 and MLL2 were removed, all phenotypic defects found in the single CKO retinae became much more severe. Notably, the double CKO mutants produced null ERG responses along with severely affected phototransduction gene expression (Figures 2,8), massive reactive gliosis (Figure 6) and apoptosis (Supplemental Figure 6) at 1MO and rapid retinal degeneration after 1MO (Figure 3). However, compound heterozygotes of Mlll and Mll2 mutants produced significantly less severe ERG defects than the double $C K O$ mutants, which was comparable to those in single $C K O$ mutants MLL2 in their redundant functions.

The functional redundancy between MLL1 and MLL2 was specific to this pair of MLLs. We previously reported that the Mll1/Mll3 double CKO retinae produced a phenotype similar to that seen in single Mll1 CKO retinae (Brightman et al., 2018). MLL1 or MLL2 formed a complex distinct from those formed by other MLL family members, which provided a possible explanation for the redundant roles of MLL1 and MLL2. We proposed MLL1 and MLL2 acted together to regulate the neuronal proliferation, development and survival in the retina (Figure 10). Although we emphasized the redundant functions of MLL1 and

407 MLL2 in this study, we did not rule out distinct functions of each gene, particularly for unique 408 mechanisms of action at the molecular level. As an example, previous studies reported both MLL1 and 409 MLL2 regulated Hox gene expression essential for body patterning during development, but they bound 
on distinct Hox loci with MLL1 on HoxA and HoxC and MLL2 on HoxB (Glaser et al., 2006; Milne et al.,

411 2002; Yu et al., 1995). Future studies are needed to determine the molecular mechanisms underlining

412 MLL1/MLL2 redundant functions in the retina, including their individual actions on specific neurons.

The mechanisms underlying retina layer thinning and functional deficits in Mll1/Mll2 double CKO

415 samples.

417 One major phenotype of Mll1/Mll2 deficiency was the thinning of retinal layers and the loss of specific

types of neurons. In P0 Chx $10 \mathrm{Cr} \mathrm{C}^{+} \mathrm{Mll} \mathrm{I}^{\mathrm{fff}} \mathrm{Mll}^{\mathrm{fff}}$ retinae, the numbers of early-born neurons and expression

419 levels of specific transcription factors were comparable to controls. Thus, the genesis and cell

specification of the early-born neurons were normal. However, the development and maintenance of rods,

421 M-cones, horizontal and amacrine cells were negatively affected at P14 (Figure 5) and 1MO (Figure 4),

422 along with increased apoptosis throughout the first 4 weeks of postnatal development (Supplemental

423 Figure 6).

425 Both cell autonomous and non-autonomous mechanisms were involved. The cellular mechanisms for the

426 loss of rods were more complex, and likely involve cell non-autonomous (secondary) effects. Key

427 observations included, firstly, the majority of rods survived between P14 to $1 \mathrm{MO}$ with shorter segments.

428 At 1MO, apoptosis was apparent to cells at INL, not to ONL cells. Secondly, significant injury-induced

429 reactive gliosis was present in the $1 \mathrm{MO} C h x 10 \mathrm{Cr}^{+} \mathrm{Mll}^{f f} \mathrm{Mll} 2^{\mathrm{fff}}$ retinae, correlating cellular stress in

430 general. Lastly and most importantly, the removal of both Mll1/Mll2 for developing rods (by $\mathrm{Nrl}$-Cre) did

431 not produce rod functional deficits or cell loss. In addition, rod degeneration as secondary effects by

432 neuronal loss at INL has been reported. For example, the loss of horizontal cells due to Onecut1 and

433 Onecut2 TF deficiency induced subsequent rod degeneration (Sapkota et al., 2014). 
In contrast, the M-cone phenotype was largely attributed to a cell autonomous mechanism, as M-cone defects was observed in retinae with Chx10-Cre and Mcone-Cre mediated Mll1/Mll2 deficiency. Notably, Mll1/Mll2 deficiency only affected the M-cones, not S-cones. The mechanisms for such specificity of the MLL actions on cone subtypes remain to be determined. Further studies are needed to determine if 439 protein factors regulating the $\mathrm{S} / \mathrm{M}$ cone gradient or cone opsin expression are affected in the double CKO 440 mutants.

442 Defects in neurogenesis may also contribute to retinal thinning and reduced cell numbers in INL of the 443 double CKO, particularly during the first two weeks of postnatal development. P0 Chx10Cre $\mathrm{Mll1}^{\mathrm{fff}} \mathrm{Mll}^{\mathrm{fff}}$ retinae had reduced number of Ki67+ and EdU+ co-labelled cells, suggesting Mll1 and Mll2 collectively affect S-phase entry of retinal proliferating cells. This was consistent with published studies from mouse brain tissue and human cancer cell lines (Chen et al., 2017; Denissov et al.,

447 2014; Jakovcevski et al., 2015; Kerimoglu et al., 2017). In our previous study, Chx10Cre Mll $^{\text {fff }}$ showed an insignificant decrease in S-phase cell number, while this study presented a further decline in the double $C K O$ retinae, suggesting a potential redundancy of $M l l 1$ and Mll2 in regulating S-phase entry of retinal progenitors. Our EdU pulse-chase experiments at P0 to P14 showed that after cell cycle exit, P0

451 progenitor cells in the double CKO retinae could produce all four types of late-born cells, namely, rods,

452 ON-bipolar cells, amacrine cells and Muller glial. Together with the unchanged number of early-born neurons at P0, these results suggested that Mll1 and Mll2 did not regulate retinal cell-type specification. Although there was a reduction of ON-bipolar cells in EdU pulse-chase experiments from P0 to P14, the overall bipolar cell numbers were unchanged at 1MO. Further studies are required for examining the

456 functions of MLLs in different windows of the retinal development. neurons. The presynaptic proteins Ctbp2/RIBEYE and VGLUT1 were present at the outer plexiform layer 
461 (Supplemental Figure 14) of the double CKO retinae, although we could not conclude if synaptic

462 connections were functional. The most likely explanation was the decrease in phototransduction, based on

463 two observations: 1) the absence of A-waves indicating no signals of ERG response, and 2) the

464 downregulation of key rod and cone phototransduction genes. It was unclear if other mechanisms

465 affecting phototransduction were involved.

467 It remains to be determined if gene misregulation in specific neurons of Mll1/Mll2 deficient retinae is due

468 to altered histone H3 K4-methylation. We attempted to address this question by examining changes of

469 rod-specific gene expression and chromatin occupancy of the H3K4me3 mark. Our surprising finding was

470 that in spite of the downregulation of rod-specific genes, normal H3K4me3 signals were detected at the

471 regulatory regions of these genes in Chx10-Cre mediated Mll1/Mll2 knockouts. Instead, H3K4me3

472 changes were seen in the regulatory regions of constitutively expressed genes that were unknown to have

473 rod-specific functions. Thus, both $\mathrm{H} 3 \mathrm{~K} 4 \mathrm{me} 3$-dependent and independent mechanisms may attribute to the

474 misregulation in rod functional development and maintenance. It is possible that the misregulation

475 mechanisms involved in minor cell types, such as M-cones, horizontal and amacrine cells might be

476 different from those of rods. Cell type-specific knockout and single cell-related approaches are needed to

477 elucidate these mechanisms.

\section{CONCLUSIONS}

481 In conclusion, this study is the first kind to address the redundancy functions of MLLs in neuroretinal

482 development and maintenance. Our findings highlight the complex functions of the MLL1 and MLL2 in

483 neuronal cell types. Our findings may inform the pathogenesis of the syndromic neurological disorders

484 associated with human $M L L 1$ and $M L L 2$ mutations and phenotype variability. 


\section{MATERIALS AND METHODS}

Transgenic mouse lines. All mice in this study were on the genetic background of $C 57 B L / 6 J$ (the Jackson Laboratory, Stock No: 000664) free of $r d 1$ and $r d 8$ mutations. The Cre, Mll1 flox, Mll2 flox mouse lines were obtained from various published colonies. Both male and female mice were used in experiments.

All animal procedures were conducted according to the Guide for the Care and Use of Laboratory Institutional Animal Care and Use Committee.

Histology and immunohistochemistry (IHC). Eyes were enucleated at various ages with the

505 All slides were mounted with hard set mounting medium with DAPI (Vectashield, Vector Laboratories,

506 Inc., CA).

508 For IHC staining of retinal cryo-sections, eyes were fixed in $4 \%$ paraformaldehyde after the removal of

509 lens for 1 hour. Eyes were then immersed in increasing concentrations of phosphate-buffered sucrose

510 solutions, and incubated overnight at $4{ }^{\circ} \mathrm{C}$ in $20 \%$ phosphate-buffered sucrose solution. Eyes were 
511 incubated in a 1:1 mixture of OCT (optimal cutting temperature; Sakura Finetek) and 20\% phosphate-

512 buffered sucrose for 1 hour. Eyes were embedded in OCT and snap frozen. Blocks were sectioned at

$5135 \mu \mathrm{m}$. Blocking and antibody staining were processed as described above.

515 For IHC staining of whole flat-mount retinae, eyes were fixed in 4\% paraformaldehyde for at least 6

516 hours. Retinae were dissected and blocked in the blocking buffer for 2 hours. Retinae were incubated with

517 primary antibodies at $4{ }^{\circ} \mathrm{C}$ overnight, followed by $1 \mathrm{X}$ PBST wash for 10 minutes, and then incubated with

518 secondary antibodies for 3 hours. Upon a final 1X PBST wash for 10 minutes, retinae were placed flat on

519 slides. All images were taken on a Leica DB5500 microscope.

EdU labelling. Edu labelling was performed with the Click-iT EdU Assay Kit (Invitrogen, ThermoFisher

522 Scientific). Mice were IP injected with $10 \mu \mathrm{L}$ of $10 \mathrm{mM}$ Edu per gram mouse weight at P0. Eyes were

523 fixed and paraffin embedded with procedures described above. EdU staining was done according to the

524 manufacturer's protocol. IHC staining was done prior to EdU staining for experiments involved both 525 steps.

527 Morphometry and cell count analysis. Thickness of retinal layers were measured on the H\&E images at 528 specific locations from the optical nerve head. Results of measurements were plotted in a spider graph.

529 For cell counting analysis, numbers of fluorescent objects were tallied in the entire cross-section. At least 5304 biological replicates of each genotype were used in the statistical analysis. Two-way ANOVA with 531 multiple comparisons or Student's t-test were performed with $\mathrm{P}<0.05$, CI:95\% using Graphpad Prism 8 532 (GraphPad Software, CA).

534 Electroretinogram (ERG). Whole animal ERGs were performed on 1- and 2-month-old mice using 535 UTAS-E3000 Visual Electrodiagnostic System with EM for Windows (LKC Technologies Inc., MD). 536 Mice were dark-adapted overnight prior to the tests. The experimental procedures were adapted from the 
previously published study of our lab (Brightman et al., 2018). ERG responses of biological replicates were recorded, averaged and analyzed using Graphpad Prism 8 (GraphPad Software, CA). The mean peak amplitudes of dark-adapted A and B waves and light-adapted B waves were plotted against log values of light intensities $\left(\mathrm{cd}^{*} \mathrm{~s} / \mathrm{m}^{2}\right)$. The statistical analysis was done by two-way ANOVA with multiple pairwise comparisons (Tukey's).

543 Quantitative PCR (qPCR). Each RNA sample was extracted from 2 retinae of a mouse using the

544 NucleoSpin RNA Plus kit (Macherey-Nagel, PA). RNA concentrations were measured using a NanoDrop

545 One spectrophotometer (ThermoFisher Scientific). $2 \mu \mathrm{g}$ of RNA was used to produce cDNA using First Strand cDNA Synthesis kit (Roche, IN). Technical triplicates were run for each gene. Primers used in this study were listed in Supplemental Table 2. The reaction master mix consisted of EvaGreen polymerase (Bio-Rad Laboratories, CA), $1 \mu \mathrm{M}$ primer mix, and diluted cDNA samples. Samples were run using a two-step 40-cycle protocol on a Bio-Rad CFX96 Thermal Cycler (Bio-Rad Laboratories, CA). Data were analyzed with QBase software (Biogazelle, Belgium). The statistical analysis was done by two-way ANOVA or Student's t-test with $p<0.05, \mathrm{CI}: 95 \%$ using Graphpad Prism 8. $M l l 1 \& 2 \mathrm{KO}$, or (Chx10) CreNeg control retinas per sample as previously described (Tran et al., 2014). at room temperature. After cross-linked cells were lysed and fragmented by sonication, chromatin

557 fragments were immunoprecipitated with the antibodies to H3K4me3 (Millipore Sigma, Burlington, MA;

558 07-473), bound to Protein A/G PLUS-Agarose (Santa Cruz Biotechnology, SC2003). After extensive

559 washing, the immunoprecipitated chromatin was eluted with $50 \mathrm{mM} \mathrm{NaHCO} 31 \%$ SDS, heated to $67^{\circ} \mathrm{C}$

560 to reverse the cross-links, and the DNA purified by ethanol precipitation. Libraries were prepared using

561 the DNA SMART ChIP-Seq Kit (Clonetech, Mountain View, CA). 10 ng of ChIP DNA was used as input

562 for each sample. Libraries were sequenced on the Illumina NovaSeq6000 2x150bp. Reads were trimmed 
using Trim Galore (v0.6.7) before mapping to mm9 genome build using Bowtie (v2.4.1). Duplicates were removed and alignments cleaned for proper alignments pairs using Picard (v2.25.7) and Samtools (v1.9-

4). Peaks were called using the broad option in MACS2 (v2.1.1), merged using BEDTools (v2.27) merge function, and overlapping reads within each library were quantified using BEDTools coverage function.

567 Enrichment was compared between genotypes using EdgeR (v3.30.3) and plotting performed in R using 568 psych (v2.1.6) and ComplexHeatmap (v2.4.3) packages. Data from Aldiri et al (GSE87064) was

569 processed in same manner as above.

\section{FIGURE LEGENDS}

Figure 1. $M l l 1$ and $M l l 2$ expression in conditional-knockout retinae. (A) Diagrams of wide-type Mll1 and Mll2 genes indicating the positions of SET domains, motifs and loxP sites. Cre recombinasemediated Mll1 knockout removes exons 3 and 4 which encode the motifs of AT hooks and nuclear targeting signals (NTS) (Gan et al., 2010). Cre recombinase-mediated Mll2 knockout removes exon 2 and

577 invokes a frameshift in the mRNA (Glaser et al., 2006). (B-D) qRT-PCR analysis of Mll1 and Mll2 expression in P0, P14 and 1 month-old (1MO) mutant retinae. Results are plotted as relative expression to Chx10Cre $e^{-}$littermate controls ( $\left.\mathrm{n} \geq 4\right)$. Asterisks (**, ***, ****) denote $p \leq 0.01, p \leq 0.001, p \leq 0.0001$ respectively by one-way ANOVA with Tukey's multiple comparisons, and ns means not significant.

Figure 2. Impaired retinal function of $M l l$ mutants at 1MO. (A) Dark adapted A-wave electroretinogram (ERG) analysis of 1MO mice of the indicated genotypes. Mean amplitudes $(\mu \mathrm{V})$ are

584 plotted against stimulus light intensity. Error bars represent SEM ( $\mathrm{n} \geq 4)$. (B) Dark adapted B-wave ERG 585 analysis of $1 \mathrm{MO}$ mutant and control mice $(\mathrm{n} \geq 4)$. (C) Light adapted B-wave ERG analysis of $1 \mathrm{MO}$

586 mutant and control mice $(\mathrm{n} \geq 4)$. All statistics is done by two-way ANOVA and Tukey's multiple

587 comparisons. Asterisks (****) denote $p \leq 0.0001$, and ns means not significant. 
Figure 3. Morphological defects of Mll mutants. (A) Hematoxylin and Eosin (H\&E) cross-section staining of mature mutant and control retinae. Top panels show representative images of $1 \mathrm{MO}$ retinae of the indicated genotypes. Bottom panels show representative images of $2 \mathrm{MO}$ or $3 \mathrm{MO}$ retinae of the indicated genotypes. Red asterisks indicate mislocalized cells. ONL: outer nuclear layer; INL: inner nuclear layer; GCL: ganglion cell layer. Scale bar $=100 \mu \mathrm{m}$ for all image panels. $(\mathbf{B})$ ONL thickness $(\mu \mathrm{m})$ in $1 \mathrm{MO}$ retinae at the indicated positions from the optic nerve head (ONH). SUP and INF indicate superior and inferior sides of the retina. Error bars represent SEM $(\mathrm{n} \geq 4)$. (C) INL thickness in $1 \mathrm{MO}$

596 mutant and control retinae ( $\mathrm{n} \geq 4)$. (D) Outer segment (OS) thickness in $1 \mathrm{MO}$ mutant and control retinae 597 ( $\mathrm{n} \geq 4)$. All statistics is done by two-way ANOVA and Tukey's multiple comparisons. Results of statistical analysis between the double $\mathrm{CKO}$ and $\mathrm{CreNeg}$ retinae are shown. Asterisks (**, ***, ****) denote $p \leq$ $0.01, p \leq 0.001, p \leq 0.0001$ respectively.

Figure 4. Altered cell type composition in $C h x 10 C r e^{+} M_{l l 1}^{f f f} M_{l l 2}^{f f f}$ at 1MO. (A-G) Immunostaining of 
615

616

617

618

619

620

621

622

623

624

625

626

627

628

629

630

631

632

633

634

635

636

637

638

639

in green) for horizontal cells, and Calretinin (right panel, in green) for amacrine and retinal ganglion cells.

Nuclei are counterstained by DAPI (blue). Scale bar $=100 \mu \mathrm{m}$ for all image panels. (B) Cell counts for different retinal cell types in P14 Chx10Cre ${ }^{+} \mathrm{Mlll}^{\mathrm{ff}} \mathrm{Mll2}^{\mathrm{fff}}$ retinae, normalized to counts from $\mathrm{Ch} x 10 \mathrm{Cr} \mathrm{e}^{-}$ $($ CreNeg) littermates. Error bars represent SEM ( $\mathrm{n} \geq 3)$. Asterisks $(*, * *)$ denote $p \leq 0.05, p \leq 0.01$ respectively, ns means not significant by T-test.

Figure 6. Glia activation in $\mathbf{C h x} 10 \mathrm{Cre}^{+} \mathbf{M l l 1}^{f / f} \mathbf{M l l 2}^{f f f}$. (A) Glial fibrillary acidic protein (GFAP)

immunostaining (in red) in 1MO mutant and control retinae. Nuclei are counterstained by DAPI (blue).

Scale bar $=100 \mu \mathrm{m}$ for all image panels. (B) GFAP immunostaining in P14 mutant and control retinae.

Figure 7. Cell proliferation defects in $\mathrm{Chx} 10 \mathrm{Cr} \boldsymbol{e}^{+} \mathrm{Mll1}^{\mathrm{fff}} \mathrm{Mll}^{f f f}$. (A) Immunostaining of cell proliferation and cell cycle markers in the indicated P0 retinae: Ki67 (left panel, in green) for proliferating cells, Ki67/PH3 (center panel, Ki67 in green, PH3 in red) for cells in the M phase, Ki67/EdU (right panel, Ki67 in green, EdU in magenta) for cells in the S phase. Nuclei (center panel) are DAPI counterstained in blue.

Scale bar $=100 \mu \mathrm{m}$ for all image panels. $(\mathbf{B})$ Cell counts for proliferating cells in P0

$\mathrm{Ch}_{10 \mathrm{Cr}} \mathrm{Mlll}^{\mathrm{fff}} \mathrm{Mll}^{\mathrm{fff}}$ retinae, normalized to counts from Chx10Cre $(\mathrm{CreNeg})$ littermates. Error bars represent SEM (n=3). Ki67+=Ki67 labelled cells, Ki67+PH3+=Ki67 and PH3 co-labelled cells, Ki67+EdU+=Ki67 and EdU co-labelled cells. (C) P14 retinal immunostaining of Rho/Calretinin/EdU (left panel, Rho in green, Calretinin in red, EdU in magenta), GS/EdU (center panel, GS in green, EdU in magenta), PKCA/EdU (right panel, PKCA in green, EdU in magenta). White asterisks indicate mislocalized cells. (D) Cell compositions of co-labelled cells in P14 retinae of the indicated genotypes.

Error bars represent SEM ( $\mathrm{n}=3)$. Results of statistical analysis are shown. Asterisks (*) denote $p \leq 0.05$, ns means not significant by T-test. Rod=rod photoreceptors, $\mathrm{AC}=$ amacrine cells, $\mathrm{ON} \mathrm{BC}=\mathrm{ON}$ bipolar cells, MG= Müller glia. 
Figure 8. Gene expression profile in P14 and $1 \mathrm{MO} C h x 10 \mathrm{Cr} \mathrm{e}^{+} \mathrm{Mll1}^{f f f} \mathrm{Mll}^{f f f}$. (A) qRT-PCR analysis of selected genes in P14 and 1MO Chx10Cre $\mathrm{Mll1}^{\mathrm{fff}} \mathrm{Mll}^{\mathrm{fff}}$ retinae. Results are plotted as relative expression expression in $1 \mathrm{MO} C h x 10 \mathrm{Cr} \mathrm{C}^{+} \mathrm{Mll} \mathrm{I}^{\mathrm{fff}} \mathrm{Mll}^{\mathrm{fff}}$ retinae. Results are plotted as relative expression to Chx10Cre ${ }^{-}$(CreNeg) littermate controls ( $\left.\mathrm{n} \geq 4\right)$. Asterisks $(*, * *, * * *)$ denote $p \leq 0.05, p \leq 0.01, p \leq 0.001$ respectively by one-way ANOVA with Tukey's multiple comparisons, and ns means not significant. (C) Quantitative comparison of data from all H3K4me3 peaks in $1 \mathrm{MO}$ CreNeg and $\mathrm{Ch} x 10 \mathrm{Cr} \mathrm{C}^{+} \mathrm{Mll} 1^{\mathrm{ff}} \mathrm{Mll}^{\mathrm{fff}}$

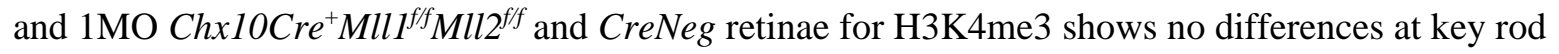
phototransduction loci.

Figure 9. Functional and morphological assessments of $1 \mathrm{MO} \mathrm{NrlCre}^{+} \mathrm{Mll}^{\mathrm{flf}} \mathrm{Mll}^{\mathrm{fff} f}$ and $\mathrm{NrlCr}^{+} \mathrm{Mll}^{\mathrm{fff}} \mathrm{Mll}^{\mathrm{fff}}$ retinae. (D) Light adapted B-wave ERG analysis of $1 \mathrm{MO} \mathrm{MconeCr} \mathrm{C}^{+} \mathrm{Mll} 1^{\mathrm{fff}} \mathrm{Mll} 2^{\mathrm{fff}}$, MconeCre $^{+} \mathrm{Mll1}^{\mathrm{fff}}$, MconeCre $\mathrm{Mll}^{\mathrm{fff}}$, and $\mathrm{Cre}^{-}(\mathrm{CreNeg})$ mice. Mean amplitudes $(\mu \mathrm{V})$ are plotted against stimulus light intensity. Error bars represent SEM ( $\mathrm{n} \geq 4)$. (E) Mopsin and PNA immunohistochemical staining in $1 \mathrm{MO}$ MconeCre ${ }^{-}$and $\mathrm{MconeCr}^{+} \mathrm{Mll}^{f f f} \mathrm{Mll2^{fff }}$ dorsal retinae. (F) Cell counts for $\mathrm{M}$ cone

661 photoreceptors in $1 \mathrm{MO}$ MconeCre $\mathrm{Mll1}^{\mathrm{fff}} \mathrm{Mll}^{\mathrm{fff}} \mathrm{MconeCr}^{+} \mathrm{Mlll}^{\mathrm{fff}}$, and $\mathrm{MconeCr}^{+} \mathrm{Mll} 2^{\mathrm{ff}}$ retinae,

662 normalized to counts from $\mathrm{MconeCre}^{-}(\mathrm{CreNeg})$ littermates. Error bars represent SEM (n=3). All statistics

663 is done by two-way ANOVA and Tukey's multiple comparisons. Asterisks (*, **, ***) denote $p \leq 0.05, p$ $664 \leq 0.01, p \leq 0.001$ respectively, ns means not significant. 
Figure 10. Summary of retinal defects in Mll1 and Mll2 conditional knockouts.

667

668

669

670

671

672

673

674

675

676

677

678

679

680

681

682

DATA AVAILABILITY

ChIP-Seq data can be retrieved from the Sequence Read Archive (SRA) PRJNA778180.

\section{ETHICS STATEMENT}

All animal procedures were conducted according to the Guide for the Care and Use of Laboratory

Animals of the National Institute of Health, and were approved by the Washington University in St. Louis Institutional Animal Care and Use Committee.

\section{AUTHOR CONTRIBUTIONS}

SC conceived of the study, CS and SC designed the experiments, CS and XZ performed experiments, CS analyzed data, PR performed bioinformatics analyses of ChIP-Seq results, CS, PR and SC wrote the manuscript. All authors read and approved the final manuscript.

\section{ACKNOWLEDGMENTS}

Authors are grateful to Mingyan Yang, Guangyi Ling and Belinda Dana for technical assistance; Dr.

Patricia Ernst and Dr. Francis Stewart for providing Mll1 flox and Mll2 flox mice, respectively. Authors thank the funding of NIH grants EY012543 (to SC) and EY002687 (to WU-DOVS), and unrestricted funds from Research to Prevent Blindness (to WU-DOVS)

\section{COMPETING INTERESTS}

The authors declare that the research was conducted in the absence of any commercial or financial relationships that could be construed as a potential conflict of interest.

\section{REFERENCES}


Aldiri, I., Xu, B., Wang, L., Chen, X., Hiler, D., Griffiths, L., Valentine, M., Shirinifard, A., Thiagarajan, S., Sablauer, A., Barabas, M.-E., Zhang, J., Johnson, D., Frase, S., Zhou, X., Easton, J., Zhang, J., Mardis, E. R., Wilson, R. K., Downing, J. R., \& Dyer, M. A. (2017). The Dynamic Epigenetic Landscape of the Retina During Development, Reprogramming, and Tumorigenesis. Neuron, 94(3), 550-568.e510.

Allis, C. D., Berger, S. L., Cote, J., Dent, S., Jenuwien, T., Kouzarides, T., Pillus, L., Reinberg, D., Shi, Y., Shiekhattar, R., Shilatifard, A., Workman, J., \& Zhang, Y. (2007). New Nomenclature for Chromatin-Modifying Enzymes. Cell, 131(4), 633-636.

Applebury, M. L., Antoch, M. P., Baxter, L. C., Chun, L. L. Y., Falk, J. D., Farhangfar, F., Kage, K., Krzystolik, M. G., Lyass, L. A., \& Robbins, J. T. (2000). The Murine Cone Photoreceptor: A Single Cone Type Expresses Both S and M Opsins with Retinal Spatial Patterning. Neuron, 27(3), 513-523.

Austin, C. P., \& Cepko, C. L. (1995). Specification of Cell Fate in the Vertebrate Retina. In B. H. J. Juurlink, P. H. Krone, W. M. Kulyk, V. M. K. Verge, \& J. R. Doucette (Eds.), Neural Cell Specification: Molecular Mechanisms and Neurotherapeutic Implications (pp. 139-143). Springer US.

Bassett, E. A., \& Wallace, V. A. (2012). Cell fate determination in the vertebrate retina. Trends in Neurosciences, 35(9), 565-573.

Blanks, J. C., Adinolfi, A. M., \& Lolley, R. N. (1974). Synaptogenesis in the photoreceptor terminal of the mouse retina. Journal of Comparative Neurology, 156(1), 81-93.

Brightman, D. S., Grant, R. L., Ruzycki, P. A., Suzuki, R., Hennig, A. K., \& Chen, S. (2018). MLL1 is essential for retinal neurogenesis and horizontal inner neuron integrity. Scientific Reports, $8(1)$, 11902.

Brightman, D. S., Razafsky, D., Potter, C., Hodzic, D., \& Chen, S. (2016). Nrl-Cre transgenic mouse mediates loxP recombination in developing rod photoreceptors. Genesis (New York, N.Y. : 2000), 54(3), 129-135.

Burmeister, M., Novak, J., Liang, M.-Y., Basu, S., Ploder, L., Hawes, N. L., Vidgen, D., Hoover, F., Goldman, D., Kalnins, V. I., Roderick, T. H., Taylor, B. A., Hankin, M. H., \& McLnnes, R. R. (1996). Ocular retardation mouse caused by Chx10 homeobox null allele: impaired retinal progenitor proliferation and bipolar cell differentiation. Nature Genetics, 12(4), 376-384.

Cenik, B. K., \& Shilatifard, A. (2021). COMPASS and SWI/SNF complexes in development and disease. Nature Reviews Genetics, 22(1), 38-58.

Cepko, C. (2014). Intrinsically different retinal progenitor cells produce specific types of progeny. Nature Reviews Neuroscience, 15(9), 615-627.

Cepko, C. L., Austin, C. P., Yang, X., Alexiades, M., \& Ezzeddine, D. (1996). Cell fate determination in the vertebrate retina. Proceedings of the National Academy of Sciences of the United States of America, 93(2), 589-595.

Chen, S., Wang, Q. L., Nie, Z., Sun, H., Lennon, G., Copeland, N. G., Gilbert, D. J., Jenkins, N. A., \& Zack, D. J. (1997). Crx, a novel Otx-like paired-homeodomain protein, binds to and transactivates photoreceptor cell-specific genes. Neuron, 19(5), 1017-1030.

Chen, Y., Anastassiadis, K., Kranz, A., Stewart, A. F., Arndt, K., Waskow, C., Yokoyama, A., Jones, K., Neff, T., Lee, Y., \& Ernst, P. (2017). MLL2, Not MLL1, Plays a Major Role in Sustaining MLLRearranged Acute Myeloid Leukemia. Cancer Cell, 31(6), 755-770.e756.

Crump, N. T., \& Milne, T. A. (2019). Why are so many MLL lysine methyltransferases required for normal mammalian development? Cellular and Molecular Life Sciences, 76(15), 2885-2898.

Denissov, S., Hofemeister, H., Marks, H., Kranz, A., Ciotta, G., Singh, S., Anastassiadis, K., Stunnenberg, H. G., \& Stewart, A. F. (2014). Mll2 is required for H3K4 trimethylation on bivalent promoters in embryonic stem cells, whereas Mll1 is redundant. Development, 141(3), 526-537. 
Dou, Y., Milne, T. A., Ruthenburg, A. J., Lee, S., Lee, J. W., Verdine, G. L., Allis, C. D., \& Roeder, R. G. (2006). Regulation of MLL1 H3K4 methyltransferase activity by its core components. Nature Structural \& Molecular Biology, 13(8), 713-719.

Dyer, M. A., Livesey, F. J., Cepko, C. L., \& Oliver, G. (2003). Prox1 function controls progenitor cell proliferation and horizontal cell genesis in the mammalian retina. Nature Genetics, 34(1), 53-58.

Eissenberg, J. C., \& Shilatifard, A. (2010). Histone H3 lysine 4 (H3K4) methylation in development and differentiation. Developmental Biology, 339(2), 240-249.

Emerson, Mark M., Surzenko, N., Goetz, Jillian J., Trimarchi, J., \& Cepko, Constance L. (2013). Otx2 and Onecut1 Promote the Fates of Cone Photoreceptors and Horizontal Cells and Repress Rod Photoreceptors. Developmental Cell, 26(1), 59-72.

Furukawa, T., Morrow, E. M., \& Cepko, C. L. (1997). Crx, a Novel otx-like Homeobox Gene, Shows Photoreceptor-Specific Expression and Regulates Photoreceptor Differentiation. Cell, 91(4), 531541.

Furukawa, T., Ueno, A., \& Omori, Y. (2020). Molecular mechanisms underlying selective synapse formation of vertebrate retinal photoreceptor cells. Cellular and Molecular Life Sciences, 77(7), 1251-1266.

Gan, T., Jude, C. D., Zaffuto, K., \& Ernst, P. (2010). Developmentally induced Mll1 loss reveals defects in postnatal haematopoiesis. Leukemia, 24(10), 1732-1741.

Glaser, S., Schaft, J., Lubitz, S., Vintersten, K., van der Hoeven, F., Tufteland, K. R., Aasland, R., Anastassiadis, K., Ang, S.-L., \& Stewart, A. F. (2006). Multiple epigenetic maintenance factors implicated by the loss of Mll2 in mouse development. Development, 133(8), 1423-1432.

Green, E. S., Stubbs, J. L., \& Levine, E. M. (2003). Genetic rescue of cell number in a mouse model of microphthalmia:interactions between Chx10 and G1-phase cell cycle regulators. Development, $130(3), 539-552$.

Gu, B., \& Lee, M. G. (2013). Histone H3 lysine 4 methyltransferases and demethylases in self-renewal anddifferentiation of stem cells. Cell \& Bioscience, 3(1), 39.

Guido, W. (2018). Development, form, and function of the mouse visual thalamus. Journal of Neurophysiology, 120(1), 211-225.

Hafler, B. P., Surzenko, N., Beier, K. T., Punzo, C., Trimarchi, J. M., Kong, J. H., \& Cepko, C. L. (2012). Transcription factor Olig2 defines subpopulations of retinal progenitor cells biased toward specific cell fates. Proc Natl Acad Sci U S A, 109(20), 7882-7887.

Hennig, A. K., Peng, G. H., \& Chen, S. (2008). Regulation of photoreceptor gene expression by Crxassociated transcription factor network. Brain Res, 1192, 114-133.

Jakovcevski, M., Ruan, H., Shen, E. Y., Dincer, A., Javidfar, B., Ma, Q., Peter, C. J., Cheung, I., Mitchell, A. C., Jiang, Y., Lin, C. L., Pothula, V., Stewart, A. F., Ernst, P., Yao, W.-D., \& Akbarian, S. (2015). Neuronal Kmt2a/Mll1 Histone Methyltransferase Is Essential for Prefrontal Synaptic Plasticity and Working Memory. The Journal of Neuroscience, 35(13), 5097.

Jones, W. D., Dafou, D., McEntagart, M., Woollard, W. J., Elmslie, F. V., Holder-Espinasse, M., Irving, M., Saggar, A. K., Smithson, S., Trembath, R. C., Deshpande, C., \& Simpson, M. A. (2012). De novo mutations in MLL cause Wiedemann-Steiner syndrome. American journal of human genetics, 91(2), 358-364.

Kerimoglu, C., Sakib, M. S., Jain, G., Benito, E., Burkhardt, S., Capece, V., Kaurani, L., Halder, R., Agís-Balboa, R. C., Stilling, R., Urbanke, H., Kranz, A., Stewart, A. F., \& Fischer, A. (2017). KMT2A and KMT2B Mediate Memory Function by Affecting Distinct Genomic Regions. Cell Reports, 20(3), 538-548.

Kim, D. S., Ross, S. E., Trimarchi, J. M., Aach, J., Greenberg, M. E., \& Cepko, C. L. (2008). Identification of molecular markers of bipolar cells in the murine retina. The Journal of comparative neurology, 507(5), 1795-1810.

Koike, C., Nishida, A., Ueno, S., Saito, H., Sanuki, R., Sato, S., Furukawa, A., Aizawa, S., Matsuo, I., Suzuki, N., Kondo, M., \& Furukawa, T. (2007). Functional Roles of Otx2 Transcription Factor in Postnatal Mouse Retinal Development. Molecular and Cellular Biology, 27(23), 8318-8329. 
Krivtsov, A. V., \& Armstrong, S. A. (2007). MLL translocations, histone modifications and leukaemia stem-cell development. Nature Reviews Cancer, 7(11), 823-833.

Le, Y. Z., Ash, J. D., Al-Ubaidi, M. R., Chen, Y., Ma, J. X., \& Anderson, R. E. (2004). Targeted expression of Cre recombinase to cone photoreceptors in transgenic mice. Mol Vis, 10, 10111018.

Li, B., Carey, M., \& Workman, J. L. (2007). The Role of Chromatin during Transcription. Cell, 128(4), 707-719.

Liu, I. S., Chen, J. D., Ploder, L., Vidgen, D., van der Kooy, D., Kalnins, V. I., \& McInnes, R. R. (1994). Developmental expression of a novel murine homeobox gene (Chx10): evidence for roles in determination of the neuroretina and inner nuclear layer. Neuron, 13(2), 377-393.

Livesey, F. J., \& Cepko, C. L. (2001). Vertebrate neural cell-fate determination: Lessons from the retina. Nature Reviews Neuroscience, 2(2), 109-118.

Livne-bar, I., Pacal, M., Cheung, M. C., Hankin, M., Trogadis, J., Chen, D., Dorval, K. M., \& Bremner, R. (2006). Chx 10 is required to block photoreceptor differentiation but is dispensable for progenitor proliferation in the postnatal retina. Proceedings of the National Academy of Sciences of the United States of America, 103(13), 4988.

Lu, Y., Shiau, F., Yi, W., Lu, S., Wu, Q., Pearson, J. D., Kallman, A., Zhong, S., Hoang, T., Zuo, Z., Zhao, F., Zhang, M., Tsai, N., Zhuo, Y., He, S., Zhang, J., Stein-O’Brien, G. L., Sherman, T. D., Duan, X., Fertig, E. J., Goff, L. A., Zack, D. J., Handa, J. T., Xue, T., Bremner, R., Blackshaw, S., Wang, X., \& Clark, B. S. (2020). Single-Cell Analysis of Human Retina Identifies Evolutionarily Conserved and Species-Specific Mechanisms Controlling Development. Developmental Cell, 53(4), 473-491.e479.

Mears, A. J., Kondo, M., Swain, P. K., Takada, Y., Bush, R. A., Saunders, T. L., Sieving, P. A., \& Swaroop, A. (2001). Nrl is required for rod photoreceptor development. Nat Genet, 29.

Mellough, C. B., Bauer, R., Collin, J., Dorgau, B., Zerti, D., Dolan, D. W. P., Jones, C. M., Izuogu, O. G., Yu, M., Hallam, D., Steyn, J. S., White, K., Steel, D. H., Santibanez-Koref, M., Elliott, D. J., Jackson, M. S., Lindsay, S., Grellscheid, S., \& Lako, M. (2019). An integrated transcriptional analysis of the developing human retina. Development, 146(2).

Meyers, R. M., Bryan, J. G., McFarland, J. M., Weir, B. A., Sizemore, A. E., Xu, H., Dharia, N. V., Montgomery, P. G., Cowley, G. S., Pantel, S., Goodale, A., Lee, Y., Ali, L. D., Jiang, G., Lubonja, R., Harrington, W. F., Strickland, M., Wu, T., Hawes, D. C., Zhivich, V. A., Wyatt, M. R., Kalani, Z., Chang, J. J., Okamoto, M., Stegmaier, K., Golub, T. R., Boehm, J. S., Vazquez, F., Root, D. E., Hahn, W. C., \& Tsherniak, A. (2017). Computational correction of copy number effect improves specificity of CRISPR-Cas9 essentiality screens in cancer cells. Nature Genetics, 49(12), 1779-1784.

Milne, T. A., Briggs, S. D., Brock, H. W., Martin, M. E., Gibbs, D., Allis, C. D., \& Hess, J. L. (2002). MLL Targets SET Domain Methyltransferase Activity to Hox Gene Promoters. Molecular Cell, 10(5), 1107-1117.

Morrow, E. M., Chen, C. M. A., \& Cepko, C. L. (2008). Temporal order of bipolar cell genesis in the neural retina. Neural Development, 3(1), 2.

Nadal-Nicolás, F. M., Jiménez-López, M., Sobrado-Calvo, P., Nieto-López, L., Cánovas-Martínez, I., Salinas-Navarro, M., Vidal-Sanz, M., \& Agudo, M. (2009). Brn3a as a Marker of Retinal Ganglion Cells: Qualitative and Quantitative Time Course Studies in Naïve and Optic NerveInjured Retinas. Investigative Ophthalmology \& Visual Science, 50(8), 3860-3868.

Nishida, A., Furukawa, A., Koike, C., Tano, Y., Aizawa, S., Matsuo, I., \& Furukawa, T. (2003). Otx2 homeobox gene controls retinal photoreceptor cell fate and pineal gland development. Nature Neuroscience, 6(12), 1255-1263.

Remez, Liv A., Onishi, A., Menuchin-Lasowski, Y., Biran, A., Blackshaw, S., Wahlin, K. J., Zack, D. J., \& Ashery-Padan, R. (2017). Pax6 is essential for the generation of late-born retinal neurons and for inhibition of photoreceptor-fate during late stages of retinogenesis. Developmental Biology, 432(1), 140-150. 
Roberts, M. R., Hendrickson, A., McGuire, C. R., \& Reh, T. A. (2005). Retinoid X Receptor $\gamma$ Is Necessary to Establish the S-opsin Gradient in Cone Photoreceptors of the Developing Mouse Retina. Investigative Ophthalmology \& Visual Science, 46(8), 2897-2904.

Roberts, M. R., Srinivas, M., Forrest, D., Morreale de Escobar, G., \& Reh, T. A. (2006). Making the gradient: Thyroid hormone regulates cone opsin expression in the developing mouse retina. Proceedings of the National Academy of Sciences, 103(16), 6218.

Rowan, S., \& Cepko, C. L. (2004). Genetic analysis of the homeodomain transcription factor Chx10 in the retina using a novel multifunctional BAC transgenic mouse reporter. Developmental Biology, 271(2), 388-402.

Ruzycki, P. A., Zhang, X., \& Chen, S. (2018). CRX directs photoreceptor differentiation by accelerating chromatin remodeling at specific target sites. Epigenetics \& Chromatin, 11(1), 42.

Sapkota, D., Chintala, H., Wu, F., Fliesler, S. J., Hu, Z., \& Mu, X. (2014). Onecut1 and Onecut2 redundantly regulate early retinal cell fates during development. Proceedings of the National Academy of Sciences, 111(39), E4086.

Shilatifard, A. (2008). Molecular implementation and physiological roles for histone H3 lysine 4 (H3K4) methylation. Current Opinion in Cell Biology, 20(3), 341-348.

Shinsky, S. A., Monteith, K. E., Viggiano, S., \& Cosgrove, M. S. (2015). Biochemical Reconstitution and Phylogenetic Comparison of Human SET1 Family Core Complexes Involved in Histone Methylation*. Journal of Biological Chemistry, 290(10), 6361-6375.

Slany, R. K. (2016). The molecular mechanics of mixed lineage leukemia. Oncogene, 35(40), 5215-5223. Soto, F., Ma, X., Cecil, J. L., Vo, B. Q., Culican, S. M., \& Kerschensteiner, D. (2012). Spontaneous Activity Promotes Synapse Formation in a Cell-Type-Dependent Manner in the Developing Retina. The Journal of Neuroscience, 32(16), 5426.

Stenkamp, D. L. (2015). Development of the Vertebrate Eye and Retina. Progress in molecular biology and translational science, 134, 397-414.

Swaroop, A., Kim, D., \& Forrest, D. (2010). Transcriptional regulation of photoreceptor development and homeostasis in the mammalian retina [Review Article]. Nature Reviews Neuroscience, 11, 563.

Szatko, K. P., Korympidou, M. M., Ran, Y., Berens, P., Dalkara, D., Schubert, T., Euler, T., \& Franke, K. (2020). Neural circuits in the mouse retina support color vision in the upper visual field. Nature Communications, 11(1), 3481.

Sze, C. C., \& Shilatifard, A. (2016). MLL3/MLL4/COMPASS Family on Epigenetic Regulation of Enhancer Function and Cancer. Cold Spring Harbor perspectives in medicine, 6(11), a026427.

Tian, N. (2004). Visual experience and maturation of retinal synaptic pathways. Vision Research, 44(28), 3307-3316.

Tran, N. M., Zhang, A., Zhang, X., Huecker, J. B., Hennig, A. K., \& Chen, S. (2014). Mechanistically distinct mouse models for CRX-associated retinopathy. PLoS genetics, 10(2), e1004111e1004111.

Turner, D. L., Snyder, E. Y., \& Cepko, C. L. (1990). Lineage-independent determination of cell type in the embryonic mouse retina. Neuron, 4(6), 833-845.

Wu, F., Li, R., Umino, Y., Kaczynski, T. J., Sapkota, D., Li, S., Xiang, M., Fliesler, S. J., Sherry, D. M., Gannon, M., Solessio, E., \& Mu, X. (2013). Onecut1 Is Essential for Horizontal Cell Genesis and Retinal Integrity. The Journal of Neuroscience, 33(32), 13053.

Wu, S., Chang, K.-C., \& Goldberg, J. L. (2018). Retinal Cell Fate Specification. Trends in Neurosciences, $41(4), 165-167$.

Yokoyama, A., Wang, Z., Wysocka, J., Sanyal, M., Aufiero Deborah, J., Kitabayashi, I., Herr, W., \& Cleary Michael, L. (2004). Leukemia Proto-Oncoprotein MLL Forms a SET1-Like Histone Methyltransferase Complex with Menin To Regulate Hox Gene Expression. Molecular and Cellular Biology, 24(13), 5639-5649.

Young, R. W. (1985). Cell differentiation in the retina of the mouse. The Anatomical Record, 212(2), 199-205. 
bioRxiv preprint doi: https://doi.org/10.1101/2021.11.15.468679; this version posted November 15,2021 . The copyright holder for this preprint (which was not certified by peer review) is the author/funder, who has granted bioRxiv a license to display the preprint in perpetuity. It is made available under aCC-BY 4.0 International license.

894 Yu, B. D., Hess, J. L., Horning, S. E., Brown, G. A. J., \& Korsmeyer, S. J. (1995). Altered Hox

895 expression and segmental identity in Mll-mutant mice. Nature, 378(6556), 505-508.

896 Zhang, T., Cooper, S., \& Brockdorff, N. (2015). The interplay of histone modifications - writers that 897 read. EMBO reports, 16(11), 1467-1481. 
Po
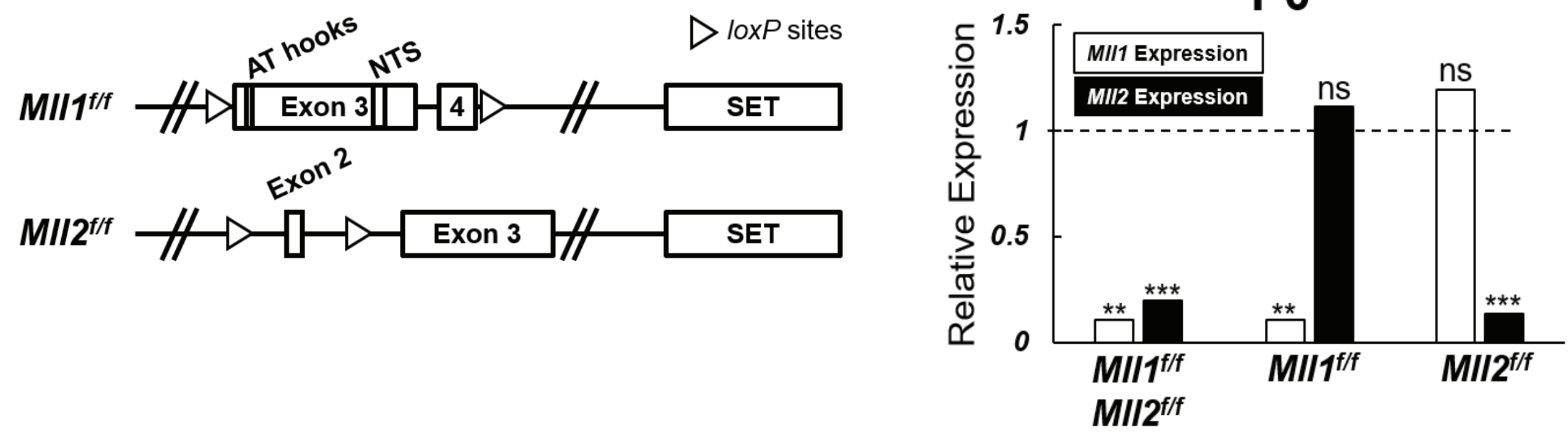

D
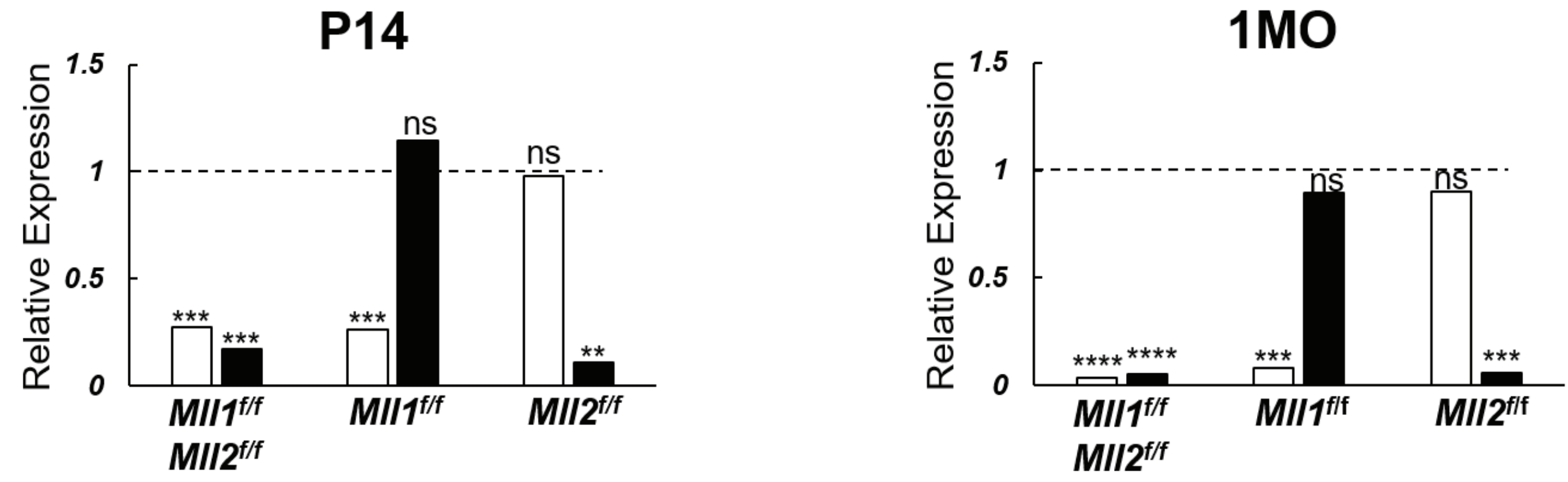

Figure 1 


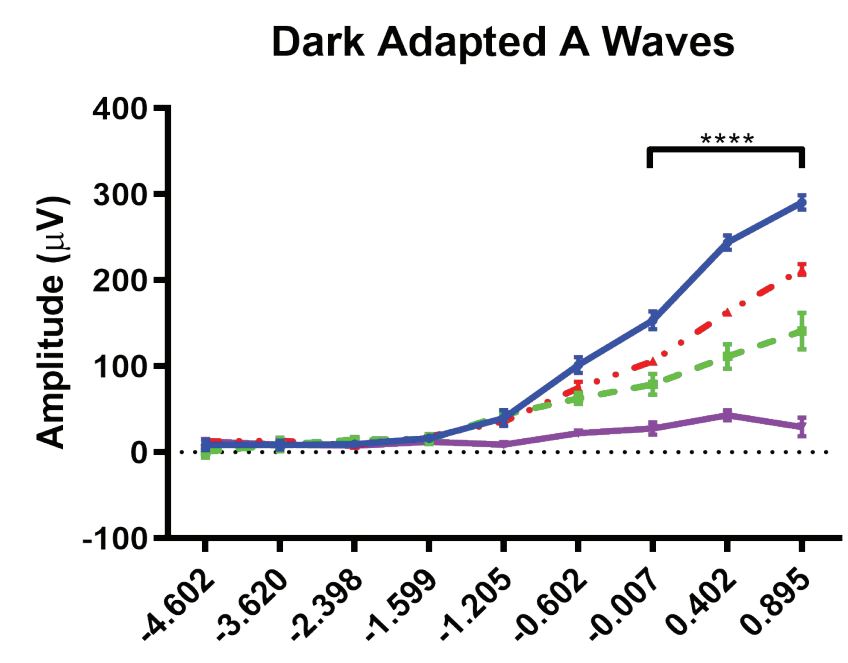

Log Light Intensity (cd*s $\left./ \mathrm{m}^{2}\right)$

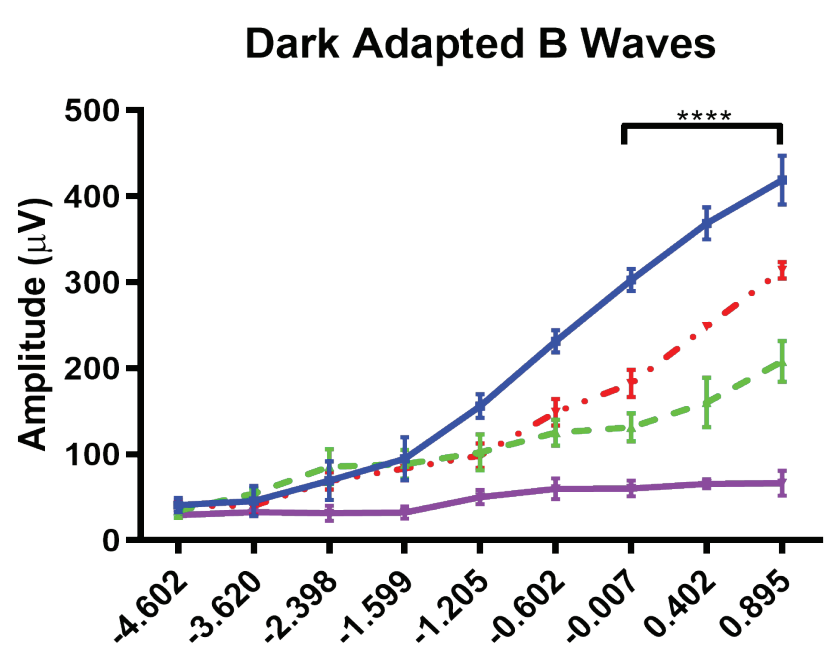

Log Light Intensity (cd* $\left.s / \mathrm{m}^{2}\right)$
Light Adapted B Waves

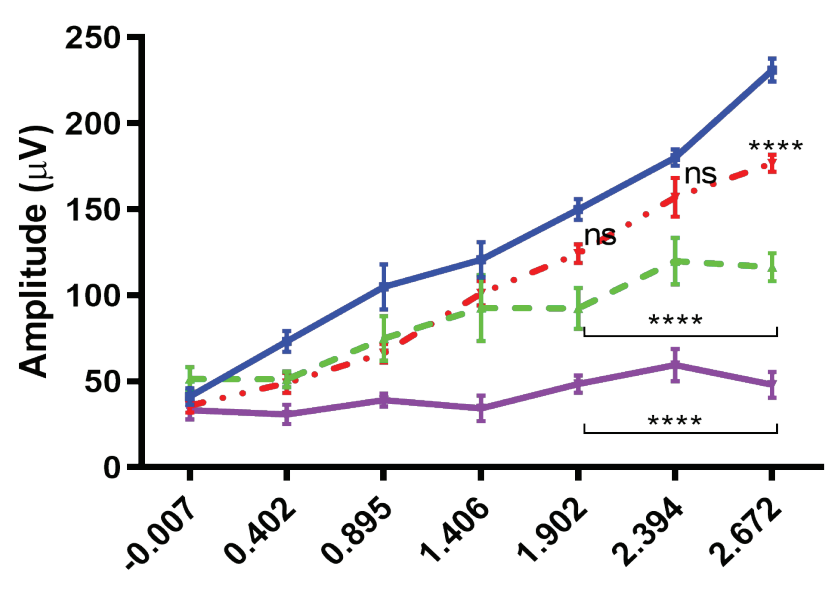

Log Light Intensity (cd $\left.{ }^{*} s / \mathrm{m}^{2}\right)$

Figure 2 


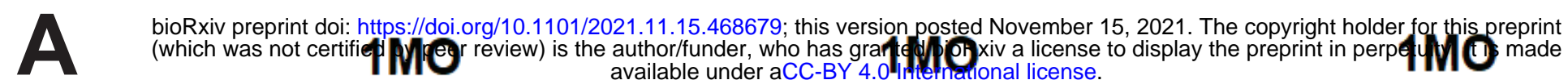

Chx10Cre-

ONL

INL

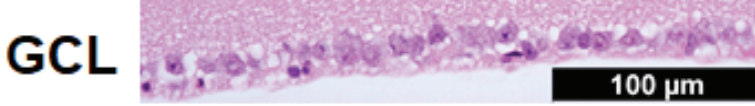
$2 \mathrm{MO}$ Chx10Cre ${ }^{+}$ MIIIf/f

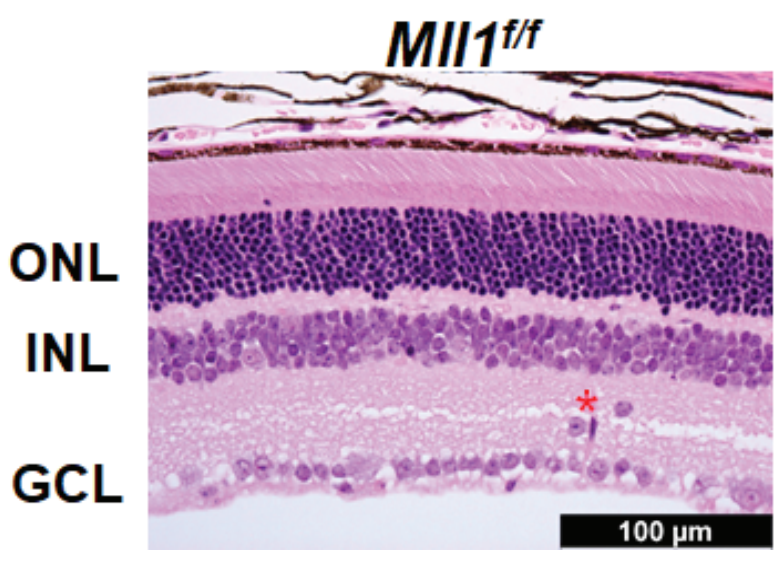

B

- CreNeg

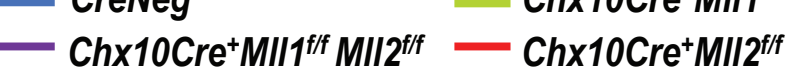

ONL Thickness

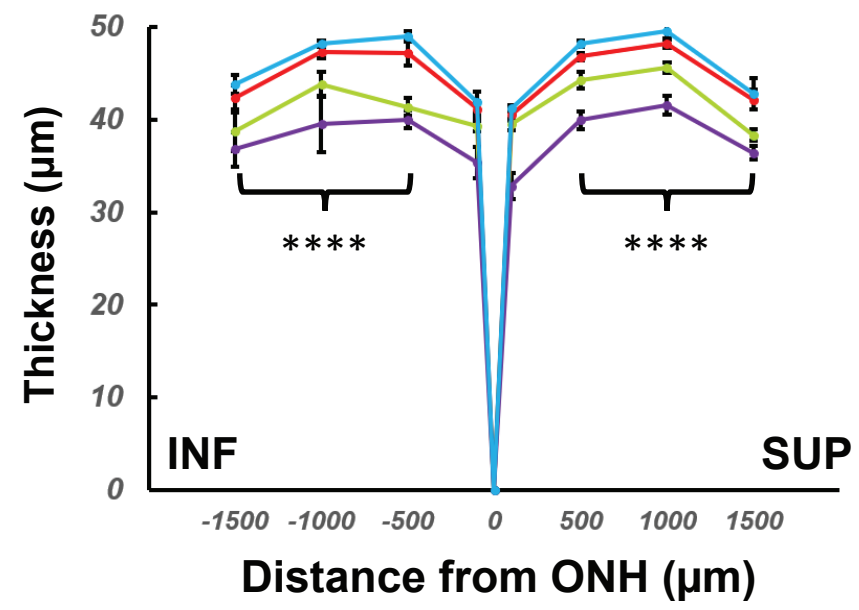
Chx10Cre ${ }^{+}$ MII1/ff

Chx10Cre ${ }^{+}$ MII2f/f

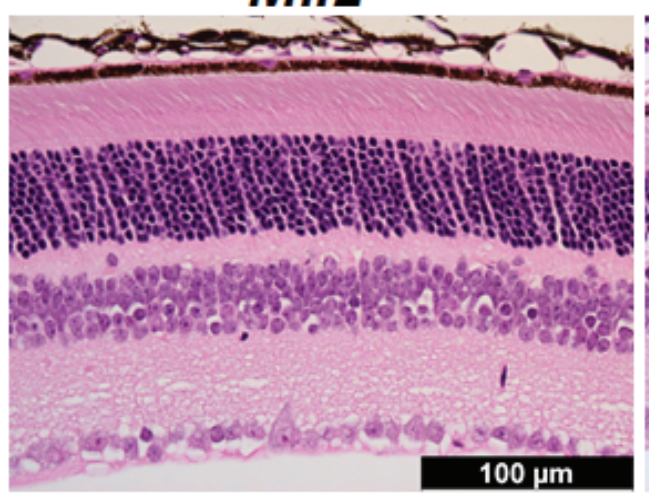

$2 \mathrm{MO}$

Chx10Cre+ MII1 $^{\text {f/f }} \mathrm{MII}^{\text {f/f }}$
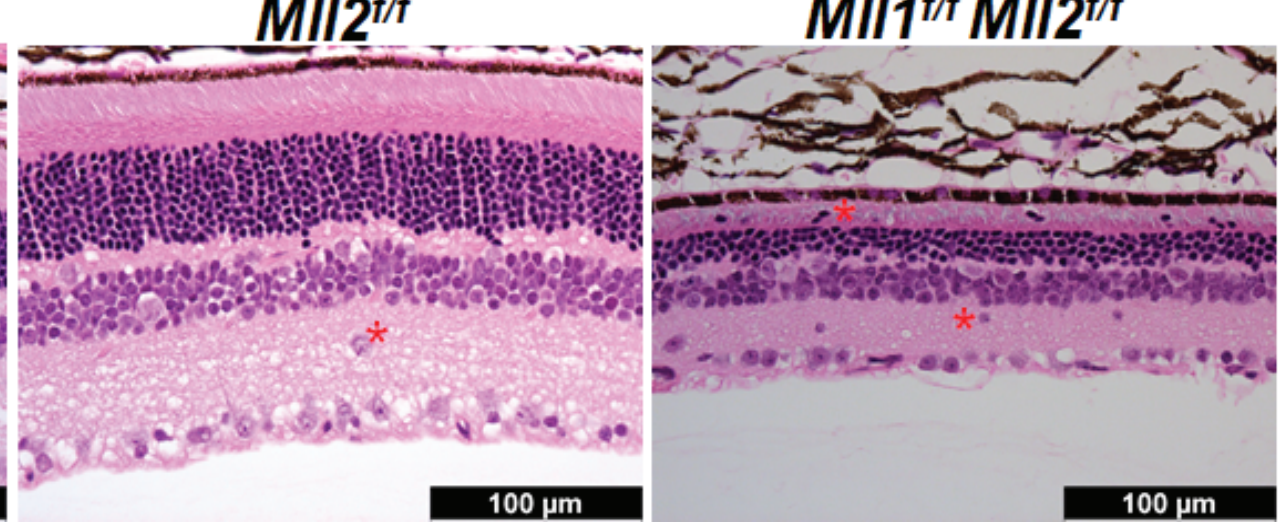

D
$1 \mathrm{MO}$

Chx10Cre+ MII1 f/f MII2f/f

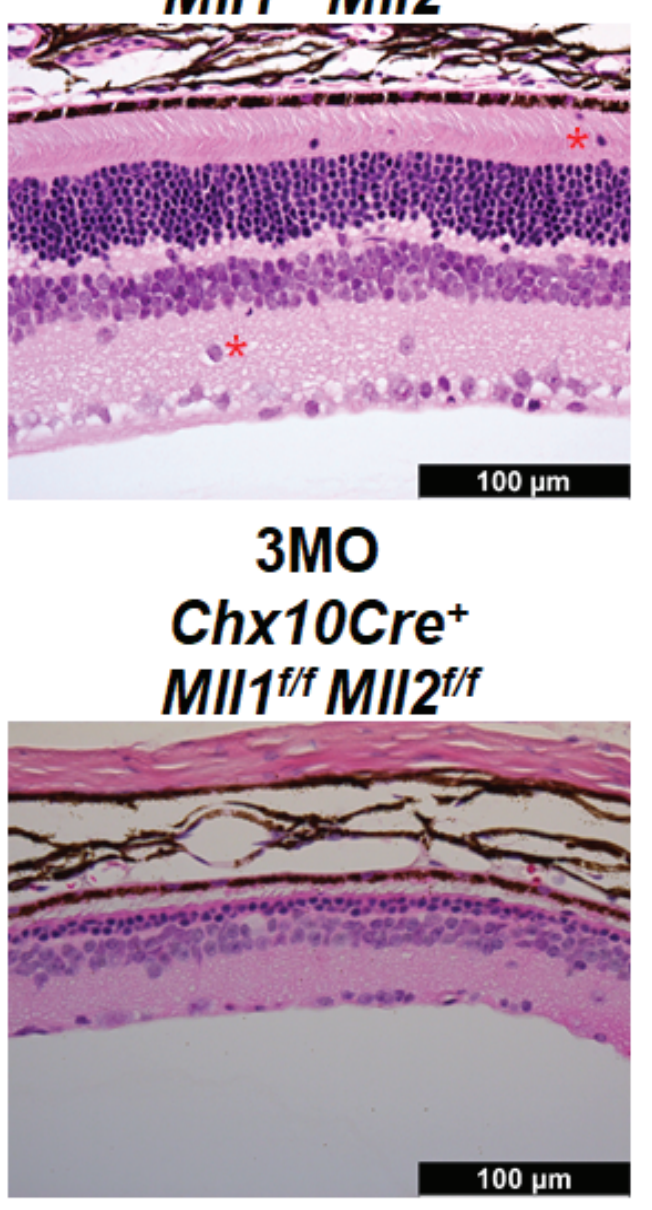

INL Thickness

OS Thickness

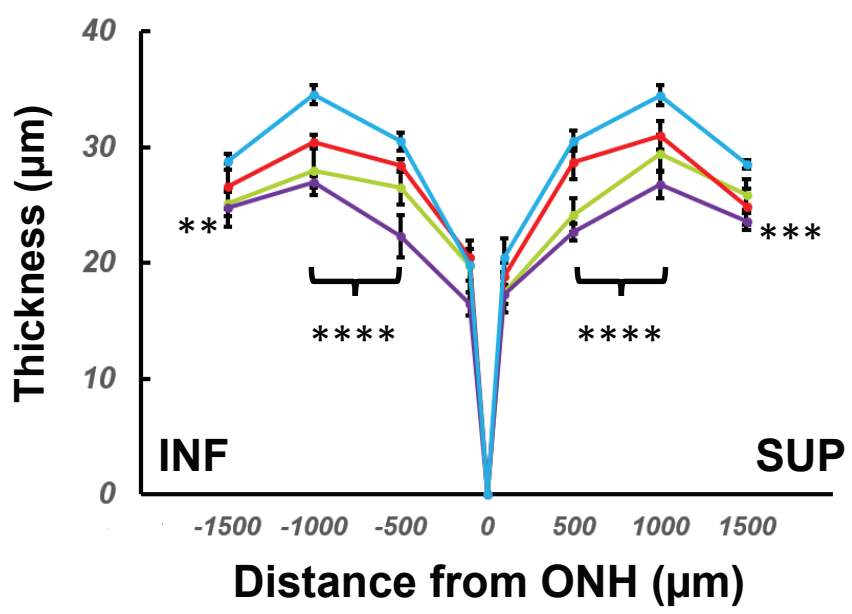

Figure 3 
$\Delta \begin{aligned} & \text { bioRxiv preprint doi: https://doi.org/10.1101/2021.11.15.4686 } \\ & \text { (which his version posted November } 15,2021 \text {. The copyright holder for this p ppint }\end{aligned}$

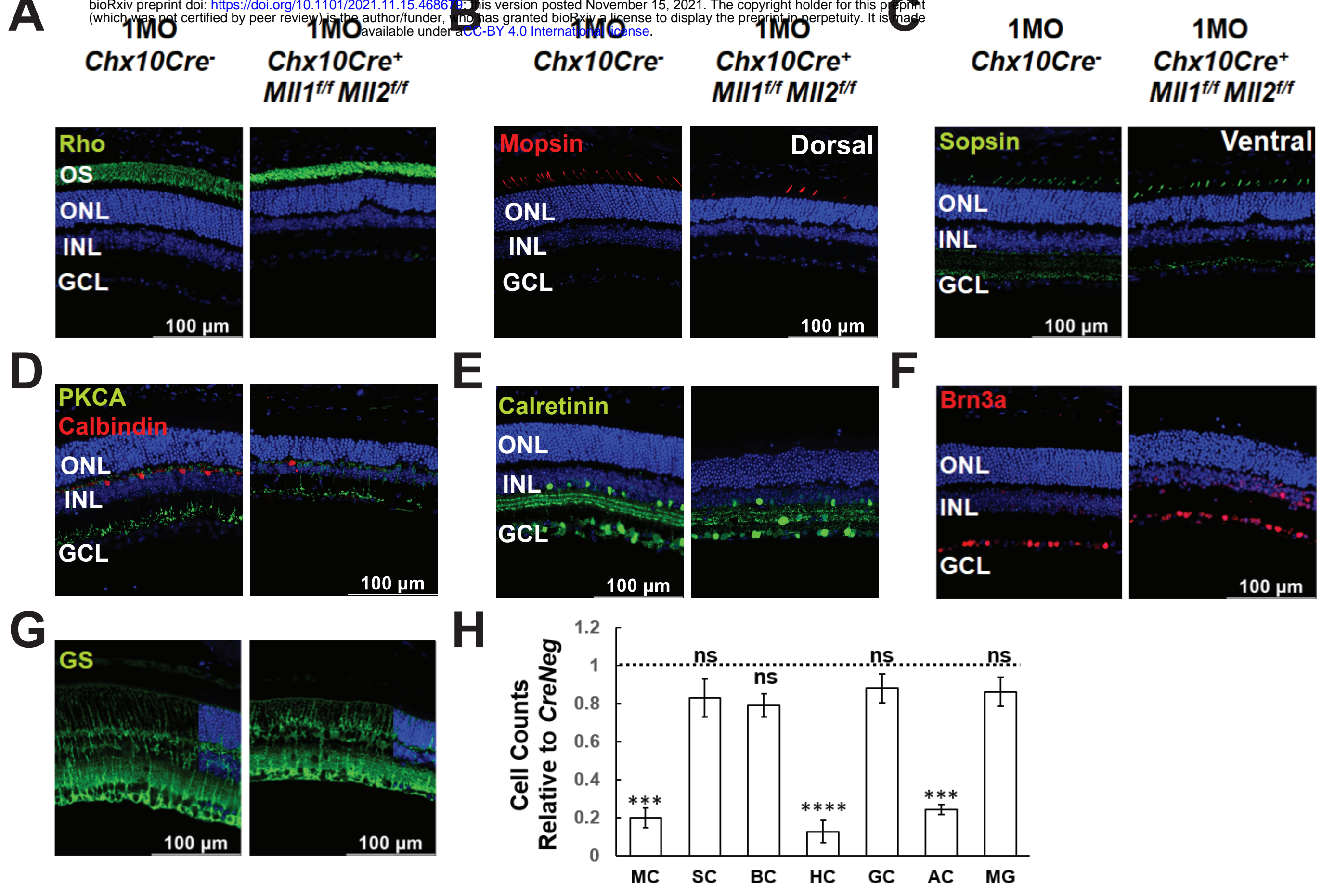

Figure 4 
$\Delta \quad$ bioRxiv preprint doi: https://doi.org/10.1101/2021.11.15.468679; this version posted November 15,202 De copyright holder for this preprint (which was not certified by peer review) is the author/funder, who has granted bioRxiv a license to display ) preprint in perpetuity. It is made Cone Arrestin available under aCC-BY 4.0 Internationahlicense.
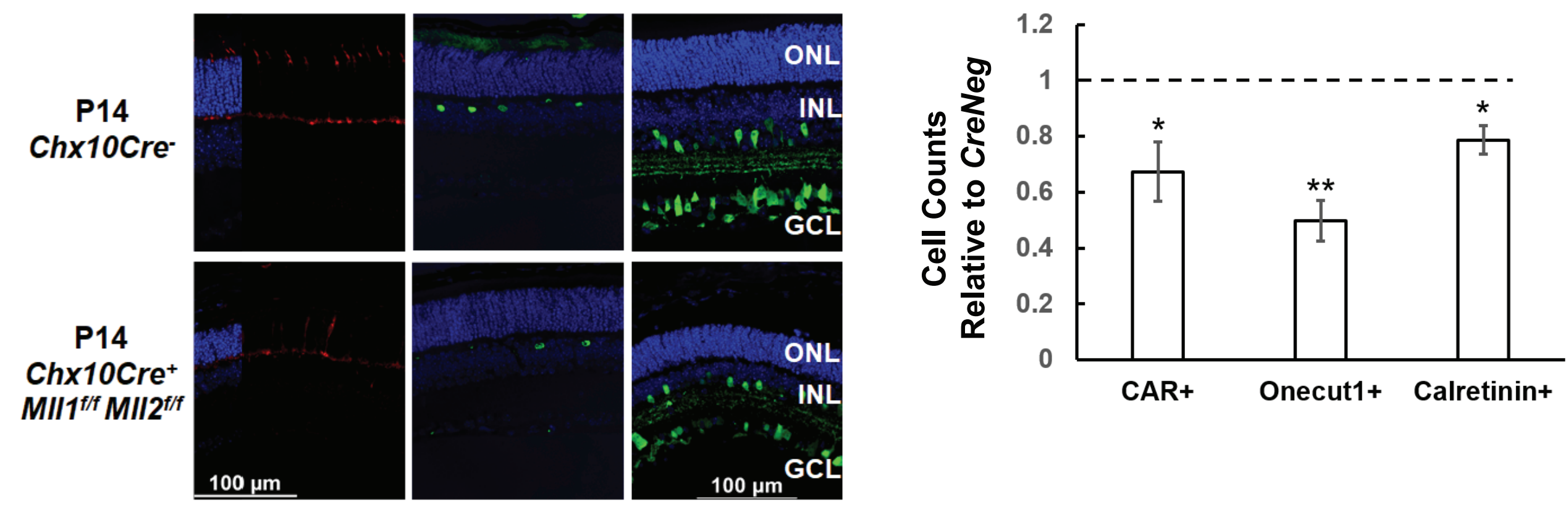

Figure 5 


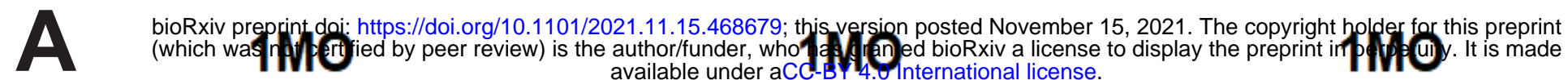

\section{Chx10Cre-}

Chx10Cre+

MIII/f
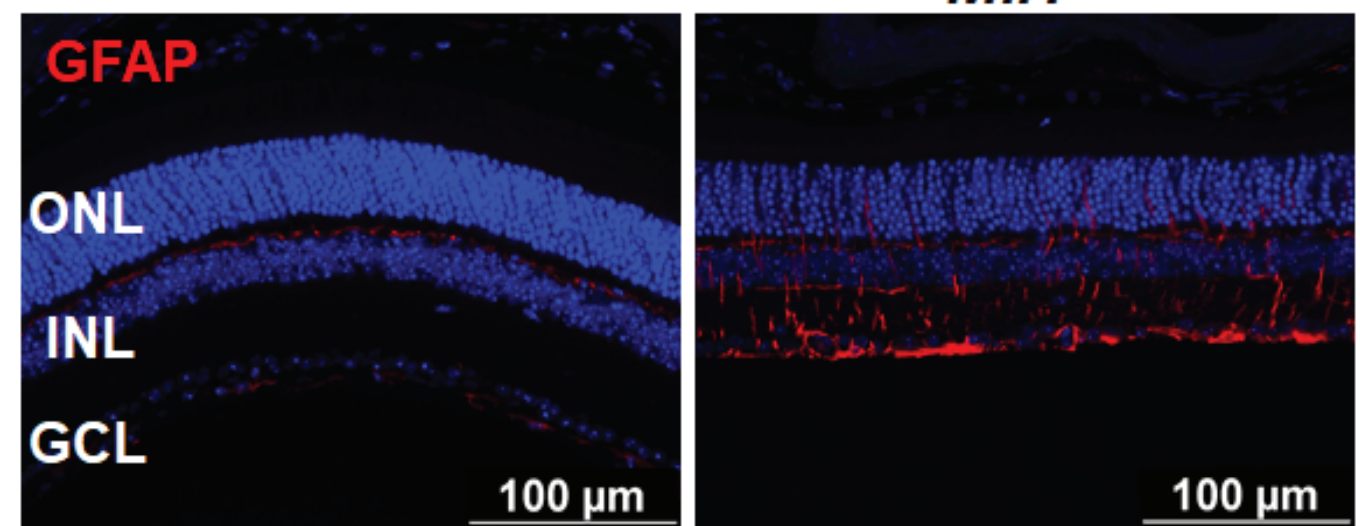

P14

Chx10Cre- Chx10Cre+

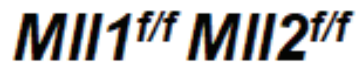

\section{B}
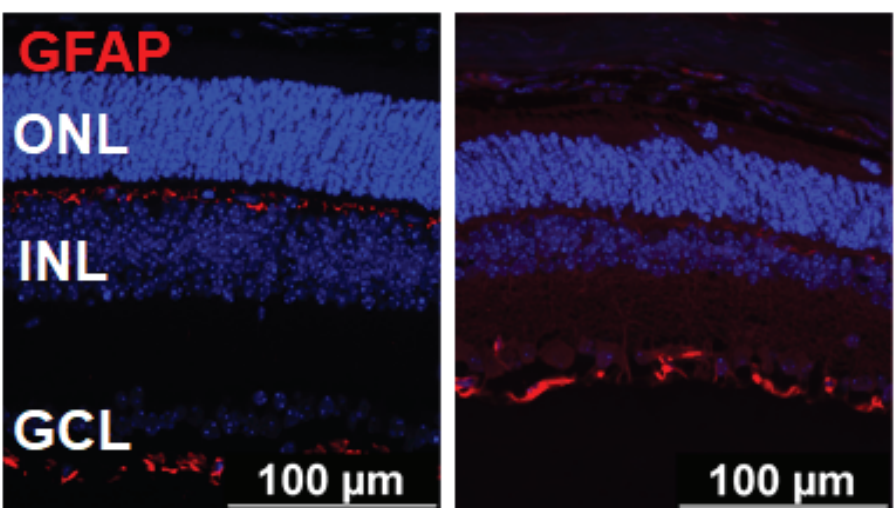

Chx10Cre ${ }^{+}$ MIIIf/f

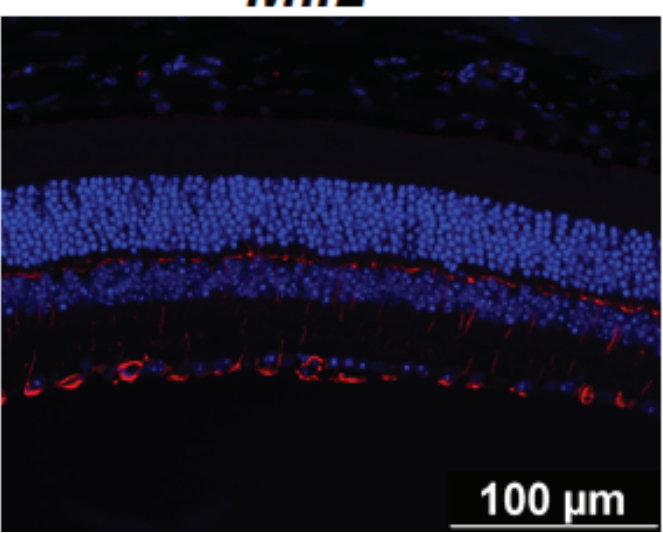

Chx10Cre ${ }^{+}$ MII1 ${ }^{f / f} M I I 2^{f / f}$

\begin{tabular}{l|c}
\multicolumn{1}{l|}{ Chx10Cre- } & $\begin{array}{c}\text { Chx10Cre } \\
M^{+}\end{array}$ \\
\hline GEAP & \\
\hline ONL & \\
\hline INL & \\
GCL & \\
\hline
\end{tabular}

Figure 6 
bioRxiv preprint doi: https://doi.org/10.1101/2021.11.15.468679; this version posted November 15,2021 . Th copyright holder for this preprint
(which was not certified by peer review) is the author/funder, who has granted bioRxiv a license to displa the preprint in perpetuity. It is made
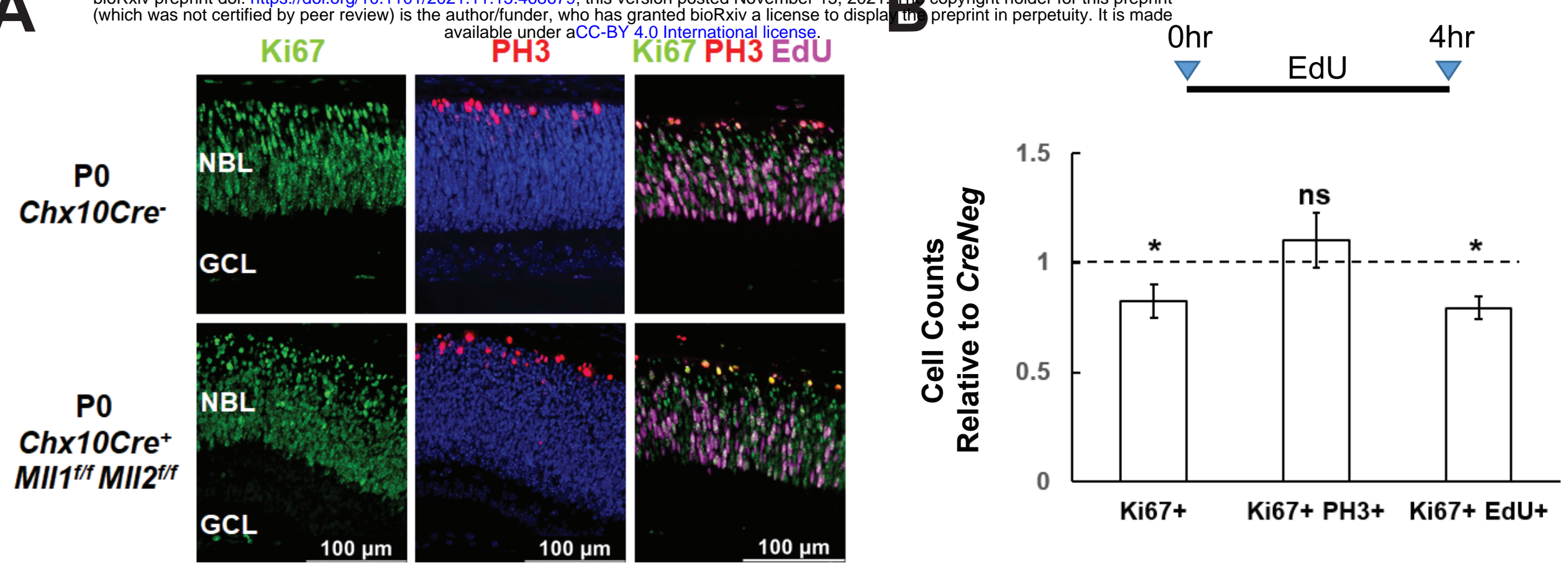

C

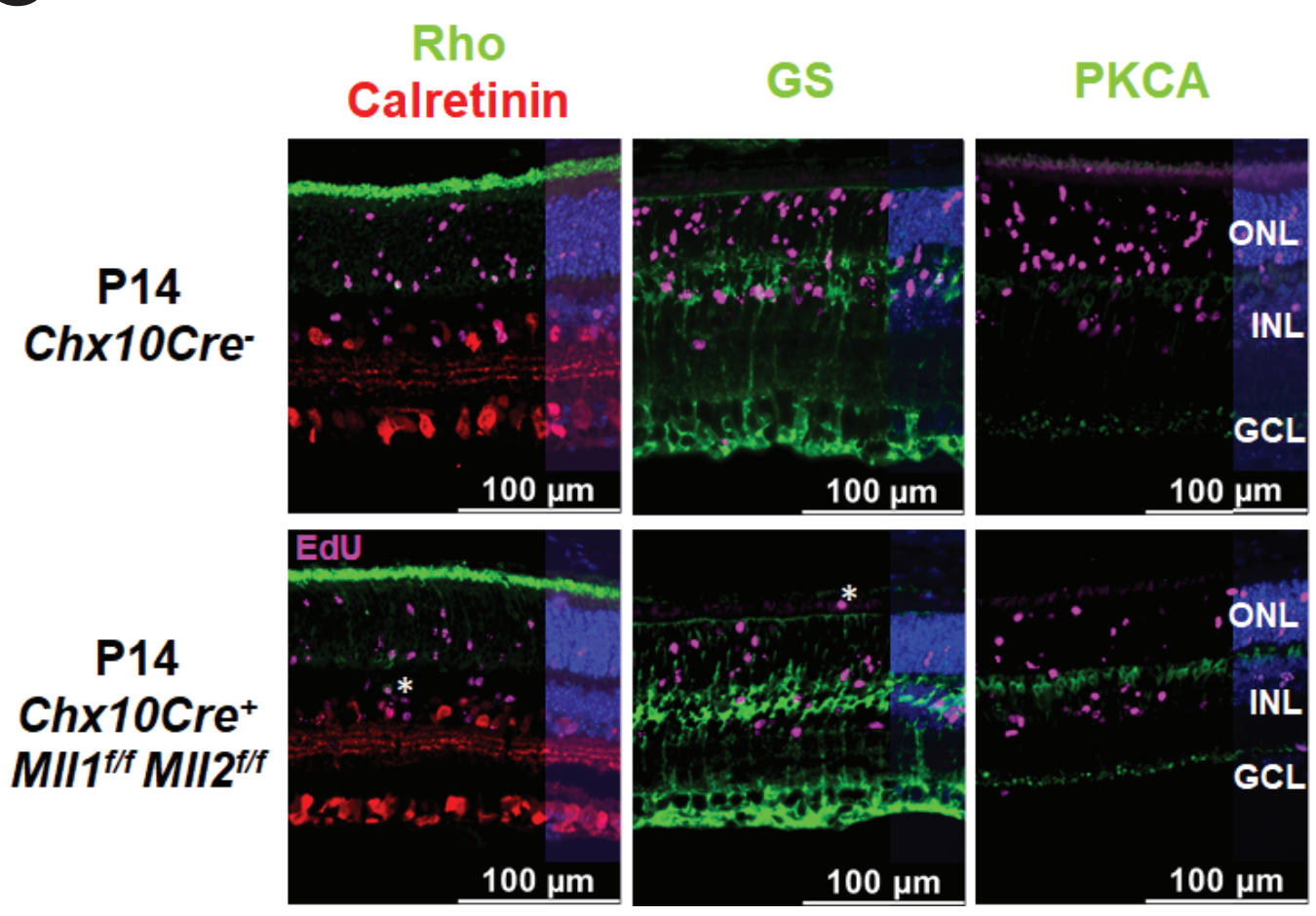

D

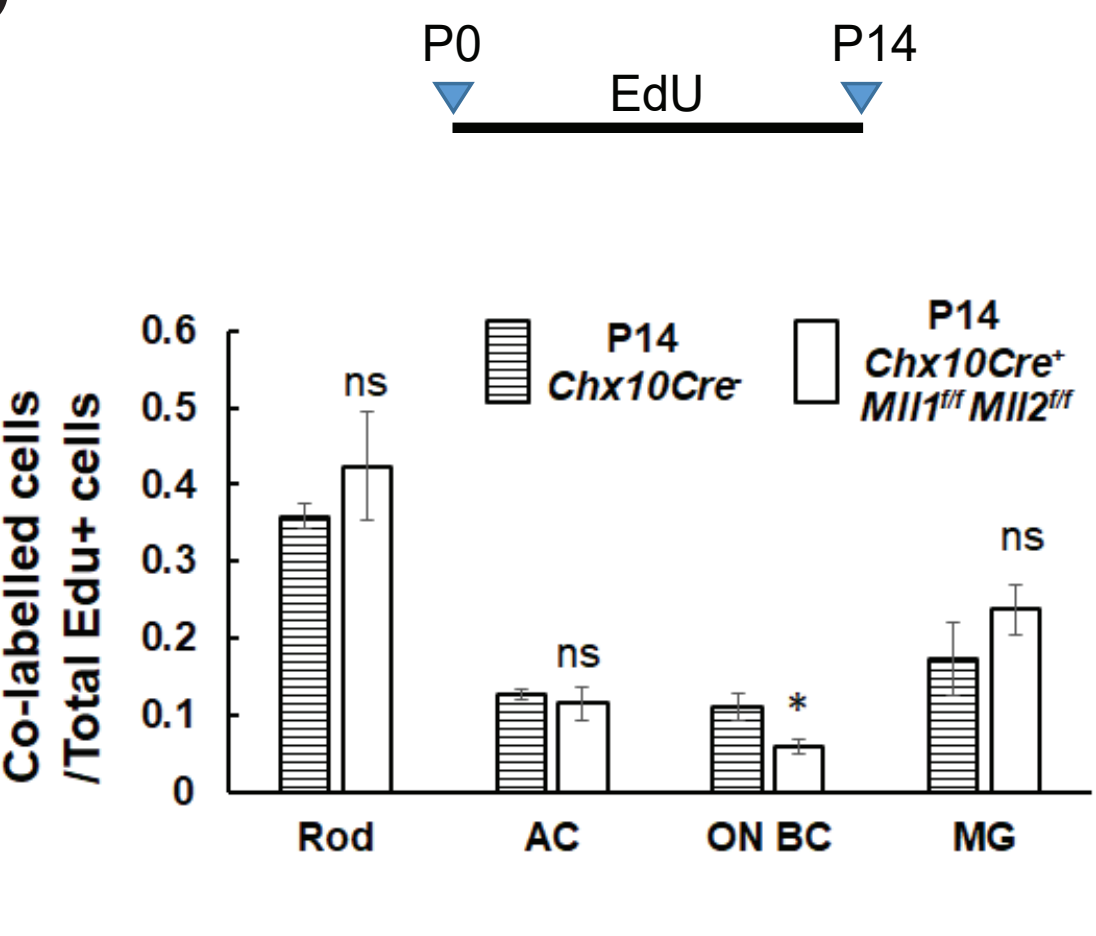

Figure 7 
bioRxiv preprint doi: https://doi.org/10.1101/2021.11.15.468679; this version posted November 15,2021 . The copyright holder for this preprint
(which was not certified by peer review) is the author/funder, who has granted bioRxiv a license to display the preprint in perpetuity. It is made
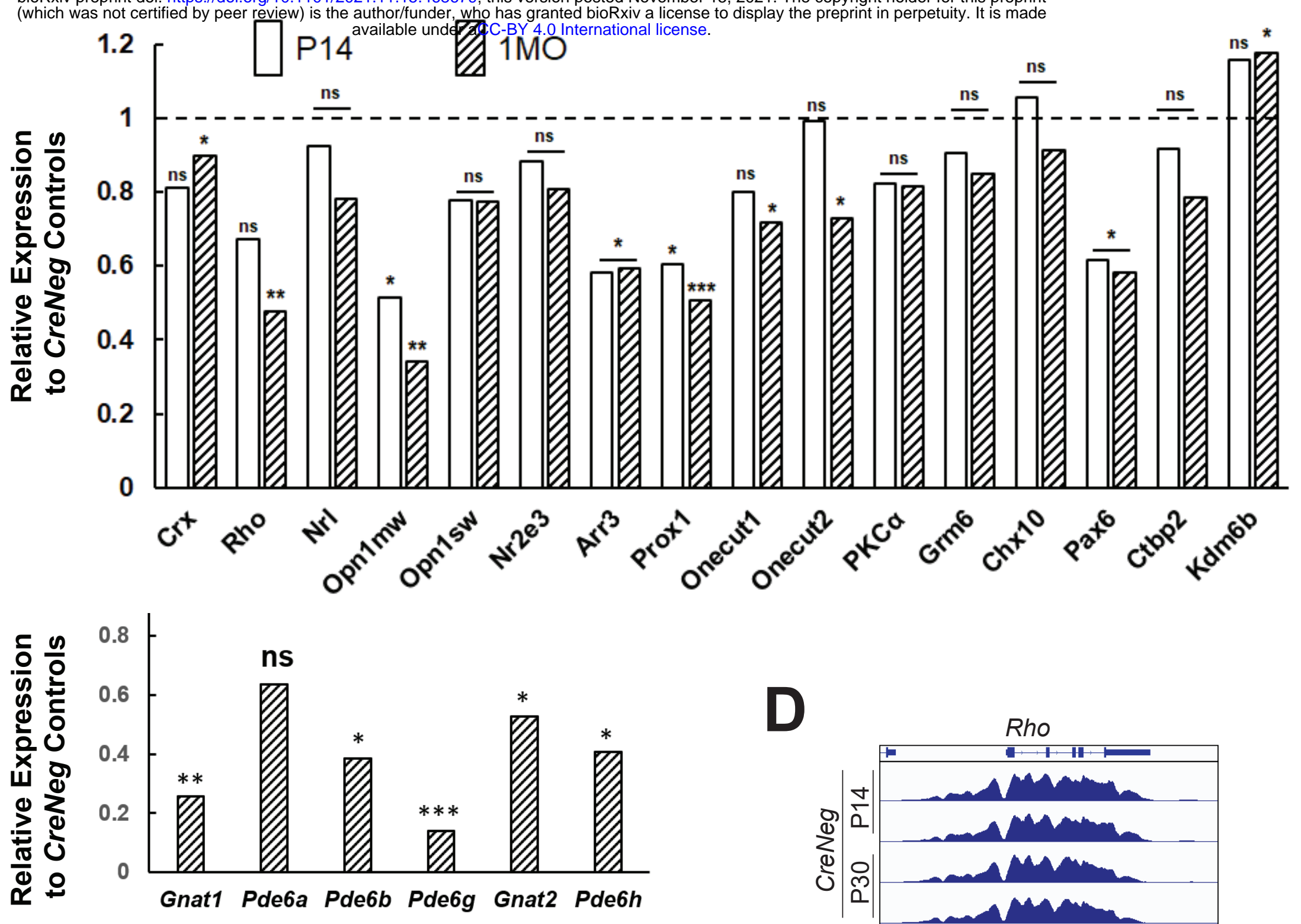

C

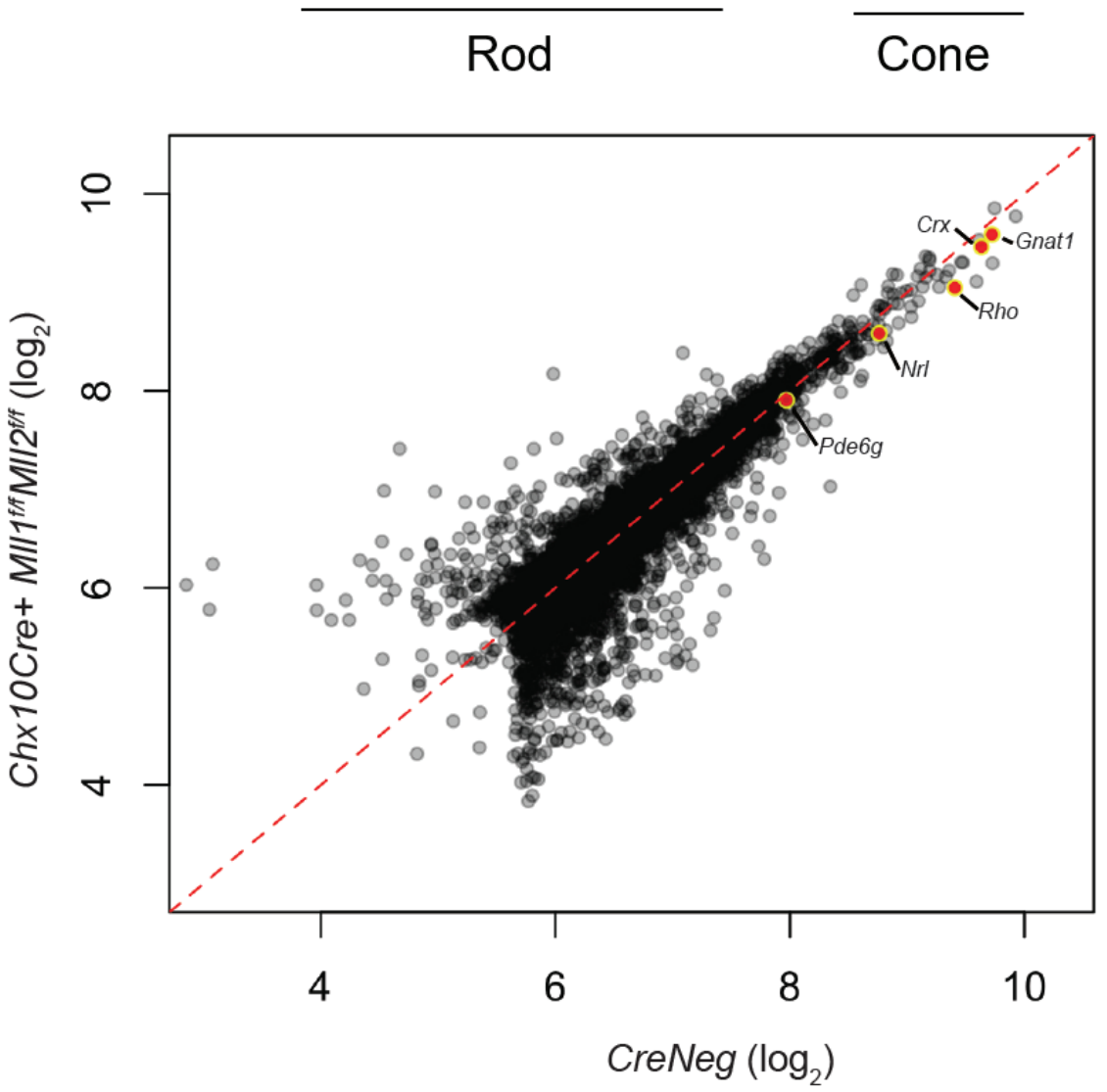

D
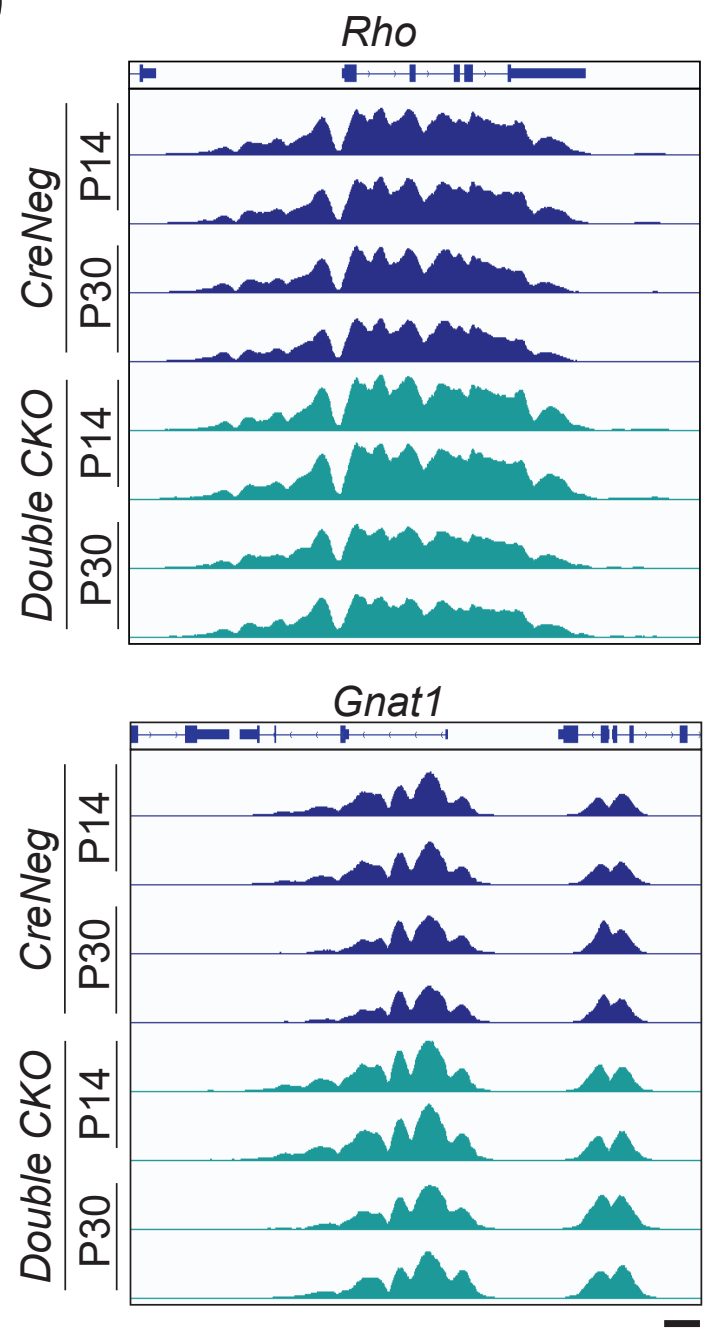

CreNeg $\left(\log _{2}\right)$ 


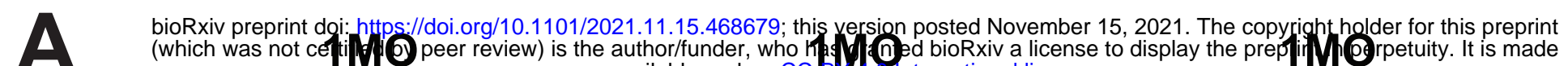

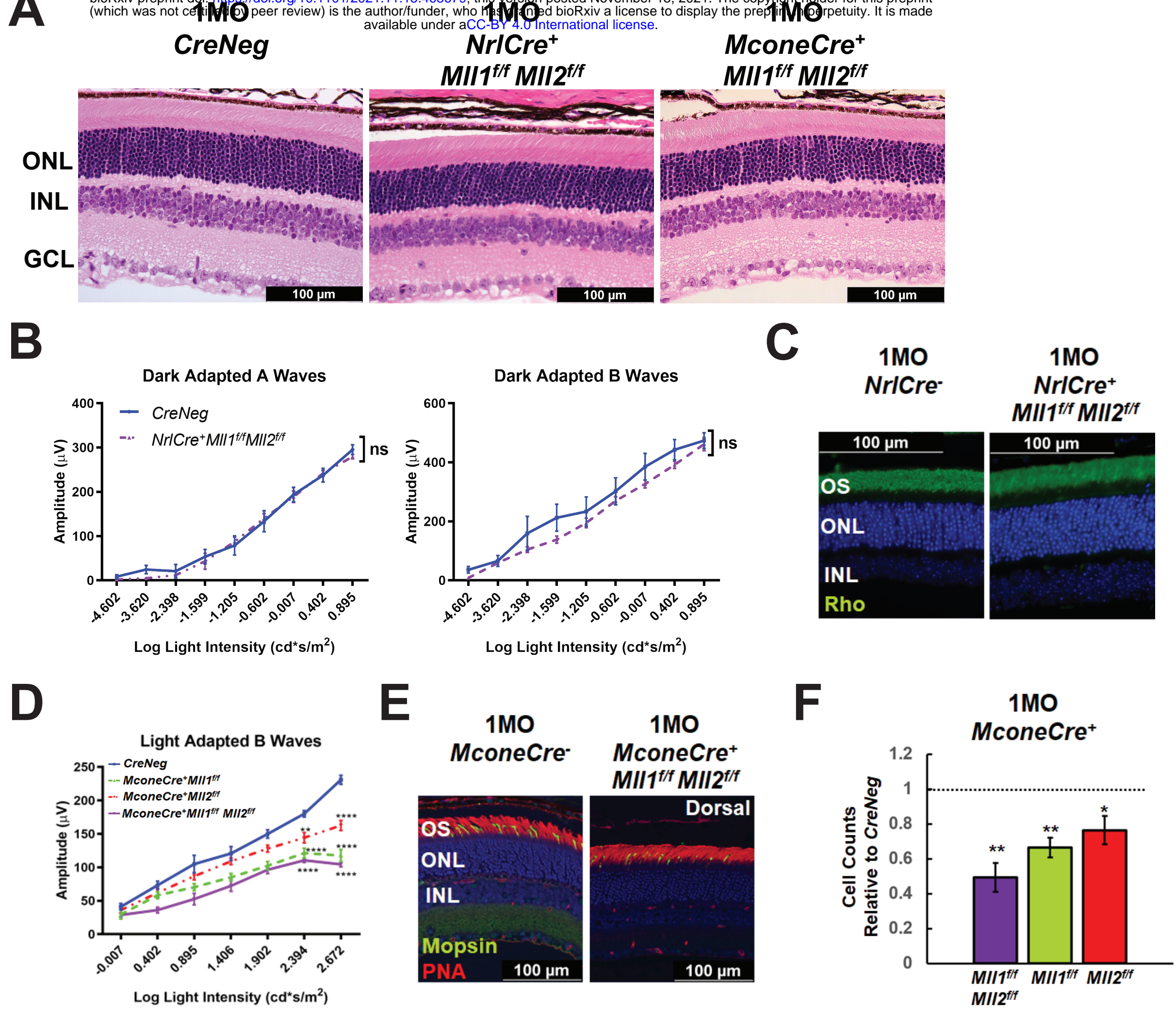


bioRxiv preprint doi: $h t t p s: / / d o i . o r g / 10.1101 / 2021.11 .15 .468679$; this version posted November 15, 2021. The copyright holder for this preprint (which was not certified by peer review) is the author/funder, who has granted bioRxiv a license to display the preprint in perpetuity. It is made

\begin{tabular}{|c|c|c|c|c|}
\hline $\begin{array}{c}\text { Normal } \\
\text { Developmental Program }\end{array}$ & \begin{tabular}{|l|} 
Proliferation \\
\end{tabular} & $\begin{array}{l}\text { Visual Function } \\
\text { Development }\end{array}$ & & Maintenance \\
\hline MLL1 or MLL2 loss & & $\underset{\text { M-cones }}{\text { Rods }^{\boldsymbol{\Lambda}}} \star$ & $\begin{array}{l}\mathrm{HC} \\
\mathrm{AC}\end{array}$ & $\begin{array}{c}\text { No Rapid } \\
\text { Degeneration }\end{array}$ \\
\hline MLL1 and MLL2 loss & & $\begin{array}{l}\text { Rods } \\
\text { M-cones }\end{array}$ & $\begin{array}{l}\mathrm{HC} \\
\mathrm{AC}\end{array}$ & $\begin{array}{c}\text { Rapid } \\
\text { Degeneration }\end{array}$ \\
\hline
\end{tabular}

Figure 10 